\title{
"I'm Not Gonna Put That On My Kids": Gendered Opposition to New Public Health Initiatives
}

\author{
Jessica McCrory Calarco, Indiana University \\ Elizabeth M. Anderson, Indiana University
}

\begin{abstract}
Our individualistic, consumeristic medical system pushes women to act as family health managers. As a result, women are generally more likely than men to follow expert medical recommendations for avoiding health risks. In the context of rampant misinformation, however, the pressure women face to control risks may lead them to disproportionately oppose some new efforts to promote public health. We investigate this possibility using a novel mixed-methods study examining gendered opposition to two school-based public health initiatives related to COVID-19. Nationally representative surveys of 1,946 parents reveal that mothers are significantly more likely than other parents to oppose school-required immunizations against COVID-19 (and significantly more likely to report planning not to vaccinate their children). This opposition is particularly prevalent among white Republican/Republican-leaning mothers (54\% opposed). Simultaneously, however, mothers are significantly less likely than other parents to oppose school mask mandates, with white Democrat/Democrat-leaning fathers being most opposed (45\%). In-depth interviews with a socioeconomically, politically, and racially/ethnically diverse group of mothers $(\mathrm{N}=64)$ link these patterns to mothers' beliefs that they can control the risks of COVID-19 (including through use of masks) but not the risks of COVID-19 vaccines. Thus, we conclude that, in the context of rampant misinformation, gendered pressures lead mothers to disproportionately support initiatives they perceive as useful for controlling health risks and disproportionately oppose initiatives they perceive as introducing uncontrollable risks. Given high rates of parental opposition to COVID-related public health initiatives, we suggest that a consumeristic model of medicine, coupled with widespread misinformation, may lead to a crisis of confidence that undermines public health.
\end{abstract}

\section{Funding and Acknowledgements}

This project was supported by the Networks, Complex Systems \& Health Project Development Team within the ICTSI NIH/NCRR Grant Number UL1TR001108, as well as through Indiana University's Social Science Research Funding Program and Indiana University's Sociological Research Practicum. We are grateful to Amelia S. Knopf, Emily Meanwell, Brea Perry, Andrew Halpern-Manners, Elaine Hernandez, and Max Coleman for feedback and support in carrying out this project, as well as to Leo Banks, Katie Beardall, Grayson Bodenheimer, Kinsey Bromm, Caroline Brooks, Callie Cleckner, Max Coleman, Cara Davies, Rachel Desmarais, Emily Ekl, E. Frieh, Natalia Fuentes-Rohwer, Melissa Garcia, Elsie Gasaway, Benjamin Hartmann, Amelia Hawbaker, Monica Heilman, Shanita Hunt, Alisha Kirchoff, Yingjian Liang, Krystina Millar, Katie Orick, Shelley Rao, Nora Weber, Tabi Wilbur, and Chavonté Wright for their assistance with data collection and analysis. 


\section{Introduction}

Under an individualistic and consumeristic medical model, people are expected to take responsibility for their health and avoid health risks (Clarke et al. 2003; Estep and Greenberg 2020; Reich 2020a; Timmermans and Oh 2010). In this system, mothers and women who may become mothers face particularly strong pressures to control risks to their families' health (Burton-Jeangros 2011; Elliott and Bowen 2018; Gage-Bouchard 2017b; Mackendrick 2014; Ranji and Salganicoff 2014; Reich 2014, 2020a; Umamaheswar and Janani 2020; Waggoner 2017). As a result, women generally report greater concerns about risks than men (Borghans et al. 2009; Rosen, Tsai, and Downs 2003) and are also more likely than men to follow expert medical recommendations (Courtenay 2000; Courtenay, Mccreary, and Merighi 2002; Denton and Walters 1999; Read and Gorman 2010; Umamaheswar and Janani 2020). Given these patterns, we might expect women to be less likely than men to oppose new public health initiatives. Yet, there is also reason to suspect that, especially when health-related misinformation is widespread (Loomba et al. 2021; Seymour et al. 2015), the gendered pressure women face to control risks will lead them to disproportionately reject some new efforts to promote public health.

We investigate this possibility using a novel mixed-methods data set and through the case of gendered opposition to two school-based public health initiatives related to COVID-19. That includes one initiative (school-required immunizations against COVID-19) that may-in the context of rampant misinformation (Loomba et al. 2021) — be perceived as a potential a risk to children's health and one initiative (school mask mandates) which is less likely to be perceived as a health risk. To further test these gendered patterns, we also consider variations in women's and men's intentions to vaccinate their children against COVID-19 and their reports of their children's mask-wearing. We use two data sources: 1) an online survey conducted in December 2020 with a nationally representative sample of US parents with children under $18(\mathrm{~N}=1,946)$ and 2) in-depth interviews with a socioeconomically, politically, and racially/ethnically diverse group of mothers with young children $(\mathrm{N}=64)$. Mothers who participated in interviews were asked the same questions about school-required immunizations against COVID-19 and school mask mandates as the parents who participated in the national survey. Thus, we can use evidence from these interviews to reveal the forces that shaped mothers' attitudes about school requirements for mask-wearing and COVID-19 vaccines.

If misinformation amplifies gendered concerns about the risks of public health initiatives, and if those concerns lead to disproportionate opposition from women, it could have troubling implications. First, because of women's role as family health managers, this opposition could negatively affect the health of individual children and families (Sobo 2016). Second, and because of women's outsized role in activism related to their children's education (Cucchiara 2013; Horvat, Weininger, and Lareau 2003; Lareau and Muñoz 2012; Lareau, Weininger, and Cox 2018; Murray et al. 2019; Posey-Maddox 2014), this gendered opposition could also undermine the success of public health initiatives involving children and schools. Third, and because parents who are skeptical about some public health interventions tend to be skeptical about other interventions (Carpiano and Chi 2018), high levels of opposition among women (and parents more generally) could point to a pending crisis of confidence in public health. 


\section{Background}

\section{Risk, Control, and Gendered Opposition to Public Health Initiatives}

Mothers are often the primary health managers for their families (Gage-Bouchard 2017b, 2017a;

Lareau 2011; Mackendrick 2014; Ranji and Salganicoff 2014). In this role, mothers and people who may become mothers are expected to identify and avoid risks to the health of their current and future children (Burton-Jeangros 2011; Elliott and Bowen 2018, 2018; Mackendrick 2014; Reich 2014, 2020b, 2020a; Umamaheswar and Janani 2020; Waggoner 2017). As Reich (2014) explains, "women are responsible for navigating meanings of health, necessity, risk, and state intervention for their children" (680). These pressures often lead women to be more concerned than men about risks (Borghans et al. 2009; Rosen et al. 2003). They also lead women to, in most cases, be more compliant than men in responding to expert medical recommendations (Courtenay 2000; Courtenay et al. 2002; Denton and Walters 1999; Read and Gorman 2010; Umamaheswar and Janani 2020).

Ironically, however, the pressure women face to avoid and control risks may be precisely what leads them to oppose some new public health initiatives. Prior research has not specifically examined whether women are more likely than men to oppose public health initiatives. Yet, research does link parents' opposition to required childhood vaccination to their perceptions of vaccine risks (Berezin and Eads 2016; Kahan 2013; Reich 2016b, 2016a, 2020a; Xiao and Wong 2020). Research has also shown that women often direct families' decisions to avoid childhood vaccinations (Estep and Greenberg 2020; Reich 2014, 2016b, 2016a, 2020a, 2020b; Sobo 2015; Sobo et al. 2016), play a central role in anti-vaccine activism (Blume 2006; Dubé, Vivion, and MacDonald 2015; Reich 2016a), and are more likely than men to trust the kinds of non-medical expert sources that often spread vaccine misinformation (Freed et al. 2011). Thus, in the context of growing attacks on the trustworthiness of medical experts (Berezin and Eads 2016; Kahan 2013; Seymour et al. 2015), we may see that women are increasingly opposed to new public health initiatives.

In this paper, we consider the possibility that mothers will be more likely than other parents to oppose school-required immunizations against COVID-19 (and more likely report that they do not have intentions to vaccinate their own children) but less likely than other parents to oppose school mask mandates. We expect that mothers will, disproportionately, see vaccines as an uncontrollable threat to their children's health while, disproportionately, seeing masks as a useful tool for controlling their children's health risks.

\section{The Case of COVID-19}

The COVID-19 pandemic is a fitting case, as it involves: 1) new public health initiatives and 2) the proliferation of misinformation about those initiatives. Both vaccines and masks are highly effective for stopping the spread of COVID-19 (Cheng, Lam, and Leung 2020; Eikenberry et al. 2020; Kim, Marks, and Clemens 2021; Polack et al. 2020). Yet, misinformation campaigns have attacked these recommendations (Hart, Chinn, and Soroka 2020; Khazan 2020; Loomba et al. 2021; Pulido et al. 2020; Wardle and Singerman 2021), portraying COVID-19 vaccines as potentially dangerous and masks as ineffective.

This misinformation is likely to generate opposition to school-based public health initiatives aimed at stopping the spread of COVID-19. Parents and politicians are already opposing school mask 
mandates (Rojas, Dobbins, and Moya 021). If schools require immunizations against COVID-19, those requirements may also generate opposition. That would be consistent with pre-pandemic efforts to weaken or overturn school immunization requirements and avoid new ones (Colgrove 2010, 2016; Diekema 2014; Estep and Greenberg 2020; Lakshmanan and Sabo 2020).

Understanding potential opposition to COVID-related school-based public health initiatives is important given schools' role in public health (Estep and Greenberg 2020; Gard and Pluim 2014). Schools conduct health screenings, provide health services, promote physical activity and healthy eating, and offer health and sex education classes (Logan and Gilmartin 2004; Luker 2007; Sparling et al. 2000; USDA 2019). In many states, public schools also require immunizations (Estep and Greenberg 2020; NCSL 2021). Through these requirements, states have helped to achieve herd immunity against once-prevalent childhood diseases (Lindley et al. 2008; Sobo 2016). Thus, public health experts have actively encouraged states to add new vaccines to the standard requirements for enrollment (Colgrove 2010; North and Niccolai 2016).

School-based public health initiatives will also be important for stopping the spread of COVID-19. Compared to older people, children are less likely to suffer serious complications (Kao, Orenstein, and Anderson 2021; Ludvigsson 2020). Children, however, can transmit COVID-19, even without showing symptoms (Laws et al. 2021; Rajmil 2020). As a result, many school districts already require masks, and some, including the Los Angeles Unified School District, have announced that they will require immunizations once a COVID-19 vaccine is widely available for children (EdWeek 2021; Rojas et al. 2021). Furthermore, and because the Sars-COV-2 virus continues to evolve new variants (CDC 2021), masks and vaccines will be necessary not only in the short-term but also for many years to come (Callaway and Ledford 2021). Identifying potential opposition to these public health initiatives can help ensure their success.

\section{Anticipating Opposition}

We anticipate that mothers and fathers may differ in their opposition toward new public health initiatives and that those differences will be related to mothers' role in managing risk. Qualitative research with college students and their families has shown that women and mothers played a key role in managing the risks of COVID-19, and that those roles led women and mothers to take more steps to manage risks (Umamaheswar and Janani 2020). Women, for example, were more likely than men to report wearing masks and taking other steps to keep their families' safe (Bhasin et al. 2020; Cassino and Besen-Cassino 2020; Haischer et al. 2020; Kramer 2020; Palmer and Peterson 2020). At the same time, research has also shown that women were less likely than men to report intentions to receive the COVID-19 vaccine (Callaghan et al. 2021; Funk and Tyson 2020). While research has not explained this apparent paradox, it is possible that women's role as family risk managers led them to be more wary of vaccines, particularly in the context of misinformation. Ultimately, then, we expect that mothers will be more likely than other parents to oppose school-required immunizations against COVID-19 but less likely than other parents to oppose school mask mandates.

Of course, gendered concerns about risk are unlikely to be only that factor that influence parents' opposition to COVID-related school public health initiatives. First, and regardless of gender, we 
might expect Republican parents to be more opposed than Democrat parents to both schoolrequired immunizations against COVID-19 and school mask mandates. Information (and misinformation) about COVID-19 has been highly politicized (Calvillo et al. 2020; Hart et al. 2020; Rothgerber et al. 2020). Compared to Democrats and those who are more liberal-leaning, Republicans and people who are conservative-leaning are less likely to perceive COVID-19 as a serious threat (Calvillo et al. 2020). Not surprisingly, then, Republicans are less likely than Democrats to report wearing masks during the COVID-19 pandemic (Bruine de Bruin, Saw, and Goldman 2020) and they are less likely to report intentions to receive a COVID-19 vaccine (Funk and Tyson 2020).

Second, we might also expect racial/ethnic differences in parents' opposition to COVID-related public health initiatives. With respect to mask mandates, we anticipate that white parents will report stronger opposition than parents from other racial and ethnic groups. This would be consistent with research showing lower rates of mask wearing among white adults than among Black, Hispanic, and Asian American adults, though those gaps have narrowed as the pandemic has progressed (Hearne and Niño 2021; Kramer 2020). With respect to school immunization requirements, however, some evidence points to stronger opposition among Black parents than among parents from other groups. Early evidence found that Black adults were less likely than white, Hispanic, and Asian American adults to report intentions to get the vaccine (Callaghan et al. 2021). More recently, however, studies have found that intentions to obtain the vaccine are weaker among white Republicans than they are among Black adults, regardless of their political affiliation (AP-NORC 2021; Diamond 2021).

Third, we might also expect differences in opposition by parents' education. Highly educated people are more likely than people with lower levels of education to report wearing masks, and they are also more likely to report intentions to receive a COVID-19 vaccine (Funk and Tyson 2020). These findings are also consistent with research linking educational attainment to the adoption of new health technologies (Glied and Lleras-Muney 2008) and adherence with medical experts' recommendations (DiMatteo 2004; Lutfey and Freese 2005). Yet, evidence also suggests that highly educated and affluent parents are particularly likely to exempt their children from required vaccines (Estep and Greenberg 2020; Reich 2016a, 2020b; Sobo 2015; Yang et al. 2015). Thus, the potential relationship between educational attainment and opposition to COVID-related school-based public health initiatives remains somewhat unclear.

\section{Methods}

In this paper, we use a mixed-methods study to investigate the source and extent of gendered variations in opposition to new public health initiatives, and we examine whether those patterns vary depending on the proliferation of misinformation that paints those initiatives as potential risks to children's health. First, and using data from surveys of a nationally representative sample of US parents, we consider gendered patterns of resistance to: 1) school-required immunizations against COVID-19 and 2) school mask mandates. We then use evidence from interviews with a socioeconomically, racially/ethnically, and politically diverse group of mothers of young children to explain the patterns we find. 


\section{Survey Data Collection, Sample, and Analysis}

This study uses data from the Institutions Trust and Decisions (ITD) Study, a nationally

representative, online survey which was conducted from November 30 through December 30, 2020 and which includes data from 2,016 US parents with children under 18. Surveys were conducted via Qualtrics. Participants were recruited through Ipsos's iSay panels. iSay panel members are invited, by email and mobile platforms, to take surveys in exchange for points which can be redeemed for incentives. Recruitment quotas (based on gender, race/ethnicity, marital status, educational attainment, income, employment status, and region) were used to recruit a probability sample that roughly corresponds with the demographics of U.S. parents with children under 18. Approximately 10,000 panelists were shown the link to the survey. 3,834 panelists clicked the link to view the survey. Of these, 1,135 were excluded because they opted not to participate, because they did not meet the selection criteria (agreeing to participate, having a child under age 18, and being at least 18 years of age), or because the quotas had been met. An additional 233 respondents completed only part of the survey and were thereby also excluded from the analysis. Post-stratification sample weights were then developed for the remaining sample $(\mathrm{N}=2,016)$, based on the American Community Survey. Weighted and unweighted estimates tended to vary only slightly. Thus, weights are only included in descriptive analyses. Missing data were handled using listwise deletion $(\mathrm{N}=70)$, resulting in a final sample of 1,946 parents. Table 1 includes demographic characteristics for the total sample and the sample used in this analysis.

\section{[TABLE 1 ABOUT HERE]}

\section{Measures}

This study includes two key binary dependent variables: opposition to school-required COVID-19 immunization and opposition to school mask mandates. In the survey, parents were asked to report how strongly they agree or disagree (7-point scale) with the following statements: 1) "Schools in my town/city should require students to receive a vaccination for coronavirus when a vaccination for children becomes publicly available" and 2) "Students in my town/city should have the choice whether to wear masks to school." With our first dependent variable, opposition to school-required COVID-19 immunization, parents receive a value of 1 ("opposed") if they indicate that they strongly disagree or disagree with the second statement and a value of 0 ("not opposed") if they indicate any of the other five responses (somewhat disagree, neither agree nor disagree, somewhat disagree, agree, strongly agree). With our second dependent variable, opposition to school mask mandates, parents receive a value of 1 ("opposed") if they indicate that they strongly agree or agree with the first statement and a value of 0 ("not opposed") if they indicate any of the other five responses (somewhat agree, neither agree nor disagree, somewhat disagree, disagree, strongly disagree).

Our analyses also include four primary independent variables: gender (whether or not the respondent identifies as a woman), educational attainment (has not completed a bachelor's degree, completed a bachelor's degree, completed an advanced degree), political affiliation (Democrat; Republican; Independent/Other), and race/ethnicity (white non-Hispanic, Black non-Hispanic, Hispanic/Latino/a, and other race/ethnicity, including multiracial). 
We also include mediating variables to examine whether parents' opposition to school public health initiatives can be explained by parents'/children's individual health behaviors.

First, we include parents' vaccine intentions for themselves and parents' vaccine intentions for their children. Parents were asked: 1) "How likely is it that you will get a COVID-19 vaccine when it becomes available?" and 2) "How likely is it that you'll get your children vaccinated for COVID-19 vaccine when a vaccine is available for children?" Responses to both questions were based on a 7-point scale ranging from "very unlikely" to "very likely." We recoded these variables into binary variables indicating strong intentions to vaccinate ("very likely" and "somewhat likely" $=1$; all other values = $0)$. For sensitivity analyses, we also tested binary variables indicating strong intentions to not vaccinate ("very unlikely" and "somewhat unlikely" $=1$; all other values $=0$ ).

Second, we include parents' mask-wearing and child's mask-wearing. Parents were asked: 1) 'The last time you were around people other than those who live with you, did you wear a mask or other face covering?" and 2) "The last time [your child] was around people other than those who live with you, did [your child] wear a mask or other face covering?" For parents with school-age children, we use the reported mask wearing behavior of their youngest school-age child. For parents without schoolage children, we use the reported mask-waring behavior of their youngest child. Possible responses to both questions included "Yes, the whole time," "Yes, part of the time," and "No, not at all." We recode these responses into binary variables indicating whether or not the parent and the focal child wore a mask the whole time. For sensitivity analyses, we also tested binary variables indicating that the parent/child never wore masks.

Our models also include a series of control variables that measure parents' backgrounds and experiences during the COVID-19 pandemic. These include relationship status (married/cohabiting; not married/cohabiting), income (five categories), employment status during the COVID-19 pandemic (employed full-time, employed part-time, not working for pay), region (Northeast, Midwest, South, West), COVID experience (whether or not the respondent has had or thinks they have had COVID19), and network COVID impact (whether any of the parent's close friends/family have had COVID19).

Models

We begin by presenting descriptive statistics for key variables used in this analysis, showing how opposition to school-required immunizations and school mask mandates vary across parents.

Next, we use conduct two parallel sets of logistic regression analyses aimed at understanding the factors that explain variations in opposition to school public health initiatives in the wake of COVID-19. The first of these predicts parents' opposition to school-required COVID-19 immunizations. The first model in this analysis includes the primary independent variables and control variables. The second model in this analysis adds parent's vaccine intentions for themselves. The third instead adds parents' vaccine intentions for their children.

The second of these predicts parents' opposition to school mask mandates. The first model in this analysis includes the primary independent variables and control variables. The second model in this analysis adds parent's mask-wearing. The third instead adds child's mask-wearing. 
Interview Data Collection, Sample, and Analysis

Next, we use data from interviews with a socioeconomically, racially/ethnically, and politically diverse group of Indiana mothers of young children $(\mathrm{N}=64)$ to explain the patterns found in our national survey data.

These mothers were interviewed as part of the Pandemic Parenting Study (PPS), a novel mixedmethods longitudinal study conducted during the COVID-19 pandemic. PPS builds on the Social Networks and Parenting Study (SNAP). From 2018-2019, we recruited pregnant women through prenatal clinics in Monroe County, Indiana. All pregnant women who attended the clinics for standard screenings for gestational diabetes (approximately 500 women) were invited to participate. 250 women agreed and consented to follow-up research. All these were invited by email to participate in the Wave 1 PPS survey.

Wave 1 of the PPS involved online surveys and in-depth interviews, with payments for each component of the project. All mothers who completed the Wave 1 survey $(\mathrm{N}=139)$ were invited to participate in in-depth interviews; roughly half of these completed Wave 1 interviews $(\mathrm{N}=65)$. Wave 1 surveys were fielded in early April 2020. Surveys were programmed in Qualtrics and emailed to participants using contact information on file. In-depth interviews were conducted from mid-April through May 2020 with the help of graduate research assistants and were audio recorded and transcribed. Wave 2 of the PPS followed the same procedures as Wave 1, with surveys and interviews conducted from January through March 2021. 45 mothers completed Wave 2 interviews, including 30 who were also interviewed in Wave 1. The PPS Wave 2 survey included the same questions about school-required immunizations against COVID-19 and school mask mandates that were included in the ITD survey. Thus, to allow for comparability across our quantitative and qualitative data, our analyses in this paper include only those mothers who completed both a PPS interview and the PPS Wave 2 survey $(\mathrm{N}=64)$. Table 2 includes demographic characteristics for this interview sample. Appendix A includes survey and interview questions used in this analysis.

\section{[TABLE 2 ABOUT HERE]}

We began our analysis by sorting interviews into four groups based on mothers' responses to survey questions about their stance on school-based public health initiatives related to COVID-19: 1) those who opposed school-required immunizations against COVID-19 but not school mask mandates, 2) those who opposed school-mask mandates but not school-required immunizations, 3) those who opposed both, and then 4) those who opposed neither. We read transcripts in each of the four groups and wrote analytic memos describing key themes in each group and identifying outliers (Miles and Huberman 1994). We then coded each transcript for evidence of key themes, which included: 1) desire to control risks to children's health, 2) concerns about the safety of vaccines, 3) perceptions of masks as a tool for controlling risks, and 4) perceptions of vaccines as a tool for controlling risks.

\section{Results}

Consistent with our expectations, we find that the gendered pressures mothers face as family health managers lead them, on the one hand, to disproportionately support new public health initiatives 
they perceive as useful for controlling risks to their children's health and, on the other hand, to disproportionately oppose medical innovations they perceive as entailing uncontrollable risks. More specifically, we find that mothers are more likely than other parents to oppose school-required immunizations against COVID-19 but less likely than other parents to oppose school mask mandates. We also find that these patterns are linked to mothers' perceptions of whether new medical innovations will help them control risks to their children's health.

\section{Descriptive Results}

Table 1 included a descriptive overview of opposition to school-required immunizations against COVID-19 and school mask mandates. Opposition to school-required immunizations is most common among mothers, Republicans, parents without bachelor's degrees, and Black and white parents (compared to Hispanic/Latino/a parents and parents of other races/ethnicities). Opposition to school mask mandates is most common among fathers, Republicans, parents who have advanced degrees, and white parents.

\section{Logistic Regression Results}

Next, we present results from two parallel sets of logistic regression analyses predicting opposition to COVID-related school public health initiatives, including parents' opposition to school-required COVID-19 immunizations and parents' opposition to school mask mandates. Each set of models begins with a base model including the primary independent variables and control variables (Models 1 and 4). The second model in each set (Models 2 and 5) adds measures of parents' behaviors (either parent's vaccine intentions for themselves or parent's mask-wearing). The third model in each set (Models 3 and 6) instead add measures of children's behaviors (either parents' vaccine intentions for children or child's maskwearing). All regression results are included in Table 3 and are presented as exponentiated coefficients.

\section{[INSERT TABLE 3 HERE]}

First, and consistent with our expectations, we find that mothers are more likely than other parents to oppose school-required immunizations against COVID-19 but less likely than other parents to oppose school mask mandates. In Model 1, mothers report significantly higher levels of opposition to school-required immunizations $(\mathrm{OR}=1.62 ; \mathrm{p}<0.01)$. By contrast, in Model 4, women report significantly lower levels of opposition to school mask mandates $(\mathrm{OR}=0.60 ; \mathrm{p}<0.001)$.

Second, we find that these differently gendered patterns are only partly explained by parents' reports of their own and their children's behaviors. In Model 2, the gender differences in opposition to school-required immunizations remain significant even after controlling for parents' vaccine intentions for themselves $(\mathrm{OR}=1.48 ; \mathrm{p}<0.05)$. By contrast, in Model 3, gender differences in opposition to school-required immunizations are no longer significant after controlling for parents' vaccine intentions for their children. With respect to opposition to school mask mandates, the gender differences remain significant even after accounting for parents' self-reported mask-wearing $(\mathrm{OR}=0.59 ; \mathrm{p}<0.001)$ and parents' reports of children's mask-wearing $(\mathrm{OR}=0.59 ; \mathrm{p}<0.001)$. 
Supplementary analyses (Appendix B) clarify these patterns. In fully specified models, mothers are significantly less likely than other parents to report intentions to vaccinate their children ("very likely" or "somewhat likely") $(0.54, \mathrm{p}<.01)$. Mothers are also significantly more likely than other parents to report that they intend not to vaccinate their children ("very unlikely" or "somewhat unlikely") (1.77, $\mathrm{p}<.001)$. As with opposition to school-required vaccines, plans to not vaccinate are particularly common among white Republican/Republican-leaning mothers (47\% are "very unlikely" or "somewhat unlikely" to vaccinate, compared to $25 \%$ of parents overall). By contrast, we find no differences between mothers and other parents in their reports of their children's mask-wearing. Roughly $70 \%$ of all parents report that their youngest school-age child wore a mask the whole time when they were last out in public, and $47 \%$ report the same for their youngest non-school-age child. Taken together, these findings suggest that concerns about risks to their children may drive parents' opposition to school-required immunizations but not opposition to school mask mandates.

Of course, gender is not the only factor predicting opposition to school-based public health initiatives. Table 3 also reveals differences by parents' political affiliations. Republican/Republicanleaning parents $(O R=4.30 ; \mathrm{p}<0.001)$ and Independent/Other party parents $(O R=1.67 ; \mathrm{p}<0.01)$ are significantly more likely than Democrat/Democrat-leaning parents to oppose school-required immunizations. Republican/Republican-leaning parents are also significantly more likely than Democrat/Democrat-leaning parents to oppose school mask mandates $(1.52 ; \mathrm{p}<0.01)$.

In addition to political variations, there are also variations by socioeconomic status and race/ethnicity. Parents without bachelor's degrees are significantly more likely than those with bachelor's degrees to oppose school-required immunizations $(\mathrm{OR}=1.54 ; \mathrm{p}<0.01)$. By contrast, parents with advanced degrees are significantly more likely than those with bachelor's degrees to oppose school mask mandates $(\mathrm{OR}=2.14 ; \mathrm{p}<0.001)$. Black parents are significantly more likely than white parents to oppose school-required immunizations $(\mathrm{OR}=1.91 ; \mathrm{p}<0.01)$. Notably, however, supplemental models reveal that white Republican parents are significantly more likely than Black parents to oppose school-required vaccines ( $45 \%$ vs. $32 \%$ opposed, $\mathrm{p}<0.01)$. White parents, Black parents, and Hispanic/Latinx parents are all roughly equally likely to oppose mask mandates, but parents who identify as another race or multiracial are significantly less likely to oppose $(\mathrm{OR}=.63$; $\mathrm{p}<0.05)$.

Families' experiences with COVID-19 are also associated with their opposition to school-based public health initiatives, in somewhat unexpected ways. Parents who have had COVID-19 are significantly more likely than parents who have not had COVID-19 to oppose school-required immunizations $(\mathrm{OR}=1.42 ; \mathrm{p}>0.05)$. They are also significantly more likely than parents who have not had COVID-19 to oppose school mask mandates (OR=1.87; $\mathrm{p}<.001)$. Having friends/family members who have contracted COVID-19 is also associated with greater opposition to schoolrequired immunizations, but these differences are only significant after controlling for parents' vaccine intentions for themselves $(O R=1.51 ; \mathrm{p}<0.01)$ and for their children $(O R=1.46 ; \mathrm{p}<0.05)$. Having close friends/family members who have contracted COVID-19 is not associated with any change in opposition to school mask mandates.

Finally, opposition to school-required immunizations against COVID-19 and school mask mandates are also linked to parents' reports of their own and their children's behavior. Models 2 and 3 show that opposition to school-required immunization is less likely among parents who report a higher 
likelihood that they will get the vaccine $(0.10 ; \mathrm{p}<.001)$ and parents who report a higher likelihood that their children will get the vaccine $(0.13 ;<.001)$. Similarly, Model 5 shows that parents likely to oppose school mask mandates if they report having worn masks $(0.69 ; \mathrm{p}<.05)$. The same is not true for parents who report that their children wore masks. Although we do not present the results here, parents' vaccine intentions for themselves and parents' vaccine intentions for children are highly correlated $(\mathrm{r}=0.74)$; parents' mask-wearing and children's mask-wearing are more weakly correlated $(\mathrm{r}=0.63)$.

Figure 1 illustrates the patterns described above, showing how opposition to school-required immunizations and school mask mandates varies across different groups of parents.

[INSERT FIGURE 1 HERE]

\section{Interview Findings}

Taken together, our regression analyses reveal that mothers are significantly more likely than other parents to oppose school-required immunizations against COVID-19 (and significantly more likely to say they will not vaccinate their children) but significantly less likely than other parents to oppose school mask mandates. These findings raise questions about why some mothers might oppose vaccines and vaccination requirements while simultaneously supporting school mask mandates and children's mask wearing more generally.

Thankfully, our qualitative interview data can answer these questions. Interviewed mothers $(\mathrm{N}=64)$ were asked the same questions about school-required immunizations against COVID-19 and school mask mandates that parents were asked in the national survey. Of the mothers we interviewed, 15 opposed school-required immunizations but not mask mandates; 1 opposed mask mandates but not school-required immunizations; 11 opposed both; 37 opposed neither. Our open-ended questions, in turn, revealed the mechanisms that produced these patterns.

Specifically, we find that, in the context of rampant misinformation, many mothers perceive themselves as able to control the risks of COVID-19 (including through the use of masks) but not the risks of COVID-19 vaccines.

\section{Opposing Vaccines, Supporting Masks}

To illustrate these patterns, we first consider mothers who opposed school-required immunizations but not school mask mandates $(\mathrm{N}=15)$. As family health managers, these mothers actively worked to control their children's exposure to health risks. These mothers also perceived themselves as more able to control the risks of COVID-19 than the perceived risks of side effects from the COVID-19 vaccine. Thus, to control their family's exposure to perceived vaccine risks, these mothers opposed school-required immunizations and planned to avoid or delay vaccinating their children. Meanwhile, these same mothers perceived masks as a useful tool for controlling their children's risk of exposure to COVID-19, so they did not oppose school mask mandates, even when they opposed schoolrequired immunizations against COVID-19. 
Renee (white, some college, strong Republican, part-time school bus driver, mother of a toddler and a second grader, pregnant) had views typical of mothers in this group (11 of whom identified as Republican or Republican-leaning Independents). Renee "strongly disagrees" that schools should require COVID-19 vaccines and "somewhat disagrees" that schools should make mask-wearing a choice. Like nearly all the mothers we interviewed, Renee described herself as the one primarily responsible for identifying and controlling her families' exposure to potential health risks. Asked about her husband's (white, some college, Republican) role in health decision-making, Renee laughed and explained:

I don't mean to make him sound like he's a kind of go-along-with-the-scheme-ofthings kind of guy, but he really is just so laid back and carefree that he does not get into the politics. He does not get into the information side of things. He's just kind of real laid back.... I'm the one that's a little bit more passionate about stuff, so he kind of listens to me. And he's just more, like, "Whatever you say honey it's cool." We joke all the time - he tells this joke not me. He tells everyone that he wears the pants in the family but I just tell him which ones to pick out and wear. [laughs]

As their families' primary health managers, mothers like Renee believed they could control their families' risk of serious consequences from COVID-19 by developing their immune. As Renee explained:

I think everybody is susceptible to it, but I think that whoever has a better immune system is more protected than those with underlying health issues.... I know that a lot of people have died. I will not dismiss that. I know a lot of people have died from complications of COVID. But I actually know a couple people personally that have survived it, even though they were given a $1 \%$ chance of survival.... Even though I do not go to church like I'm supposed to, I still consider myself a Christian. I still consider nature has the best abilities to take care of us, whether people want to admit it or not. There is a method to Mother Nature's madness and that is sorting out the weakest in every species in every herd that's on Earth. And a lot of it just goes to show it's survival of the fittest.

Mothers like Renee were often skeptical of the benefits of masks, but they ultimately decided that masks were useful for controlling COVID risks, particularly in situations where it was difficult to avoid close contact:

I mean, I see the benefits them [masks] working, but also there's so many contradictive texts out there about masks working, masks not working. Wear one, wear two.... In the beginning, they always used to say it was six feet or a mask. So if you couldn't keep six feet of distance then wear a mask. Well, now it's six feet of distance and you're wearing a mask. And I see both sides of that, I really do, but at the same time it's getting a little excessive and a little bit ridiculous. So a lot of times when I go into [the neighborhood corner store], I won't wear my mask just for the simple fact that I'm usually one of three people in there... But if it's a bigger store, or more people, or closer confines, and we can't stay socially distanced, then I do wear my mask. 
Although mothers like Renee perceived themselves as able to control their families' risks of serious consequences from COVID-19, they did not perceive themselves as able to control their families' risks of serious side effects from COVID-19 vaccines. Thus, they opposed vaccine requirements because they perceived vaccines as a bigger risk than the virus itself.

Renee: My personal opinion is that it... should be a person's choice to get it. Not mandated, because I don't always get the flu shot, but I'm not always in a situation where I need to have a flu shot because I'm able to work [only] four hours a day. I'm not around a lot of people. So my kids aren't in daycare or things like that. So a lot of times I don't see myself having to get the vaccine for the flu shot. I don't always get one for my kids. So I'm hopeful that yes it does work. But I hope that it's allowed for people to make that choice on their own.

Interviewer: Is there anything about the vaccine that worries you?

Renee: Yeah. Just in how fast it was developed. And I'm not one of those ones that thinks it alters your DNA or anything like that. [laughs] But I do see some potential risks of there being some potential side effects down the road.... It's not even been six months, so we don't even have anything to base it off of or compare it to.... They keep saying that the children are less susceptible to it [COVID-19] or are not getting as sick. So I'm not gonna put that [the risk of vaccine side effects] on my kids. I'm just gonna keep holding out until I know.

Mothers like Renee acknowledged the risks of COVID-19, but they believed they could control those by boosting their families' immune systems with vitamins, "healthy" diets, and essential oils, by avoiding close contact with others, and by wearing masks (especially when avoiding close contact was difficult). By contrast, these mothers did not perceive themselves as capable of controlling the potential risks of vaccine side effects. They saw the vaccines as riskier than the disease itself, particularly for children. Thus, they tended to oppose school-required immunizations, even when they did not oppose mask mandates in schools.

\section{Opposing both Vaccines and Masks}

Some mothers opposed both school-required immunizations and school mask mandates $(\mathrm{N}=11)$. Like mothers in the first group, these mothers (all but one of whom identified as Republican or Independent) perceived themselves as more capable of controlling the risks of COVID-19 than the risks of COVID-19 vaccines. Unlike mothers in the first group, however, these mothers were more skeptical of the benefits of masks and, in some cases, perceived masks as risky. Thus, they tended to reject efforts to mandate both vaccines and masks.

Erin (white, some college, strong Republican, full-time parent/homemaker, mother of a toddler and a preschooler), for example, "strongly disagrees" that schools should require COVID-19 vaccines for children and also "strongly agrees" that children should have the choice whether to wear masks in schools. Like mothers in the first group, Erin believed that COVID-19 is both real and harmful. 
Erin even believed she and her family had contracted COVID-19 in February of 2020. As she explained in February 2021:

My husband was laid-off, but I was working at the time in a grocery store. And I'm not exactly sure if it came from a family member who also worked in the same store or came from me and I brought it home. But my husband started first with a really, really high fever. And then then my boys did, and then me about twelve hours later. And so we have the high fevers that were prolonged and up at 101, 102, 103s. My son got up to 102 for a few days. And then we had the body aches and then the cough, the dry cough. It was just awful... But at the time it wasn't believed to have reached the US, so we didn't think anything of it and we didn't go the doctor... But the cough didn't get better for two weeks... My husband and I had it worse. It took us longer to recover. My sons, especially my youngest, he just had like a mild cough and his fever wasn't actually all that bad. [My older son] had a mild cough, but he had a high fever for almost a week. We were able to keep it managed with medicine, with like ibuprofen and all that stuff. He had to do a cool bath a couple times to help bring it down and stuff. But other than that, he just slept for like a week.

Although she acknowledged the dangers of COVID-19, Erin believed she could control her family's risk of contracting (or re-contracting) COVID-19 by staying home as much as possible and developing their immune systems.

Interviewer: Are you worried about getting infected or getting infected again?

Erin: Not really. I guess if it happens then it's going to happen. But we just we do our absolute best to stay healthy, get exercise, eat a good diet. Go outside when it's not freezing. And, you know, me and my sons, we mostly stay at home anyway. But if we have to go out, you know, I try my best to hand sanitize, wipe down our [grocery] cart and everything. But if it happens, it happens....

Interviewer: Do you ever find yourself giving advice or recommendations to people [about avoiding COVID-19]?

Erin: Yeah, like boosting your immune system, encouraging other people to get vitamin D, get some sunlight, get some exercise. Make sure you're eating a good diet. Don't be stress eating.

Meanwhile, and like other mothers in this group, Erin did not perceive herself as able to control the risks of a COVID-19 vaccine.

Erin: I'm not planning to get it and my husband's not planning to get it. I feel like it was way too rushed to know what the long-term impacts of it will be. So I don't feel comfortable until I know a lot more about it. Till there's a lot more studies done that's more thorough. Not to mention I'm pregnant and also going to be breastfeeding.... [I'm also concerned about] the contents of it and them not being open enough with everyone about what exactly goes into it, how it works, how effective it really is at protecting you from COVID-19. It's an injection that's going 
in your body that you can't reverse. So I want to know absolutely everything about it before that happens....

Interviewer: How likely do you think you would be to get the vaccine for your kids when it's available for children?

Erin: Not likely either for them as well.... And especially since they're younger, they would have to deal with who knows what kind of side effects. So I'll wait a lot longer to do that with them, with their lives, with their bodies, until we're for sure what those risks are.

Interviewer: When do you think you would feel comfortable getting it for them?

Erin: I guess it's kind of a complicated question for me. I'm not really a pro vaccinator. I see the value of some of them, but I don't do all of them and there is a family history in my side of the family of vaccine damage and autism and things like that that make vaccine damage more likely. So it's highly unlikely that they would get the vaccine period. I don't think the risk is worth it unless the medical facility or whoever does all the testing and everything was able to prove a hundred percent that there's absolutely no way that there's any kind of vaccine damage that can happen with this, which I don't really see that happening or being likely.

Like mothers in the previous group, mothers like Erin perceived themselves as more capable of controlling the risks of COVID-19 than the risks of a COVID-19 vaccine. Unlike mothers in the previous group, however, Erin and other mothers in this group did not see masks as a primary tool for controlling risks. Like Erin, some of these mothers even perceived masks as potentially increasing their risks:

If someone tells me, like: "Never leave your house. Everybody should me masked all the time," I try to remember that's usually from a place of fear and concern. And [I try to remember that just being stressed and fearful and everything just will make it worse — will make it harder on your body and make it harder to get through.... So we're going to church on Sundays. And we wear masks like how you do at a restaurant where if you're up and about moving around then you wear your mask. But if you're sitting down and you don't have to wear it, that's what we do... Because [if you're wearing masks] everyone's more reserved and being cautious and it just affects your connections with each other. Having to wear masks you can't see each other's faces very well. So that's made it more challenging and more difficult. Just dealing with all of it emotionally and mentally, and figuring out how to cope with everything... [And kids] don't have the coping skills like adults do for coping with the fear and the uncertainty of everything. They're very resilient, but just the mental capacity for coping with such big changes, big emotions isn't there yet.

Like Erin, mothers in this group linked stringent mask-wearing to high levels of fear, and they perceived fear and anxiety as more threatening to their health than COVID-19. Thus, mothers like Erin opposed not only school-required immunizations against COVID-19 but also school mask mandates, which they saw as exposing their children to the risks of high levels of fear. 


\section{Opposing Masks, not Vaccines}

Only one mother we interviewed opposed school mask mandates but not school-required immunizations against COVID-19. This mother Elise (white, some college, not strong Democrat, full-time parent/homemaker, mother of a toddler and a preschooler) "somewhat agrees" that students should have the choice whether to wear masks in school and "neither agrees nor disagrees" that schools should require immunizations against COVID-19. Like mothers in the previous two groups, Elise was concerned about potential vaccine side effects, and she perceived herself as being better able to control COVID risks than vaccine risks. Ultimately, however, Elise decided that, when the vaccine was available, it would be her responsibility to "do [her] part" by getting her family vaccinated. As she explained:

No one really knows the long-term effects of it, so that's kind of the scary part. And then I've always been on the fence about vaccines in general just because of the ingredients in them. But with all the other vaccines [for kids], we've pretty much stayed on schedule except we don't get the flu shot. So I've also been on the fence about the COVID vaccine. I'm kind of leaning more toward getting it now when it's available. Just because I feel like I wouldn't be doing my part if I didn't get it. Like, I think if no one gets it then that would defeat the purpose of having the vaccine to help get over the pandemic.... I still nurse [breastfeed] a little bit though, so I'm going to make one hundred percent sure that it would be safe for [my toddler].

Elise planned to "do her part" not only by getting vaccinated but also by having her family wear masks. Despite those efforts, however, Elise ultimately opposed school mask mandates, because she was concerned about her children's discomfort if they had to wear them all day:

[My toddler] actually does really good [with wearing a mask]. I don't take him to the store a whole lot, but I do when I have to. He knows that once we go in the store your hands are dirty, so don't touch your face, and we'll have to clean your hands. And I tell him not to touch his mask and he does awesome with it really. He doesn't play with it. Like, a lot of kids I know pull it down or don't have it on their nose or they chew on it. And he doesn't do that which is amazing. But if he had to wear one all day every day at school, I think he wouldn't like it. I mean, frankly, I don't like wearing it, either. It's not comfortable. And I was used to wearing one, because I used to be a dental assistant, so I was on and off with it all day.

Elise was the only mother we interviewed who opposed school mask mandates but not schoolrequired immunizations against COVID-19. This is consistent with our national survey findings, which show that mothers are much more likely to oppose school-required immunizations than they are to oppose school mask mandates. At the same time, Elise's comments are also useful for revealing that even mothers who identify as Democrats, who intend to get the vaccine, and who wear masks regularly may still have concerns about the risks and benefits of these public health initiatives. 


\section{Opposing neither Vaccines nor Masks}

To that end, among the 37 mothers we interviewed who opposed neither school-required immunizations against COVID-19 nor school mask mandates, many also voiced concerns about these initiatives, and particularly vaccines. Patricia (Black, some college, not strong Democrat, customer service representative, mother of two elementary-aged children and a toddler, pregnant), for example, "neither agreed nor disagreed" that schools should require COVID-19 immunizations and "strongly disagreed" that schools should make masks optional. Despite not opposing school vaccine requirements, however, Patricia did express concerns about the vaccine:

Patricia: They have told us, the CDC, that it's safe. But a lot of people are having bad reactions to it, which is leading people to believe that it's not as safe as they claim. So I'm just really still iffy about it... because I don't know how my body would react.... Like, I work for [a health insurance company], and I take member calls. And yesterday, I was talking to a member, and this guy, right after he got it, he started having a reaction.... It wasn't major, but he stated that he started getting dizzy and lightheaded and that he had to get air. And the spot where they gave him the shot was sore. And once he got air and all that stuff he started to feel better. And he was later told that that shows that his white blood cells were kicking in and it was working. Some people have told me they got a little bit of a fever right after it, and that's supposed to indicate that it's working. But all of that sounds a little iffy though! It just doesn't sound good!

Interviewer: Do you think you'll get the vaccine when one is available to you?

Patricia: I'm gonna wait it out to make sure that it's really safe-safe. Because I'm scared, like, what if I get it and then I die? Because a vaccination is basically them putting the virus in you. It's like the dormant version that that they're putting in you. And if a person never had COVID before, well I don't know how I might react to it.

Interviewer: What about if they developed one for children?

Patricia: The same thing as with me. I would be a little bit nervous. What if one of my children had a really bad reaction to it, and now they're on a breathing machine or something? I would feel bad that I just did that to my kid. So I'm gonna wait, because I know that we've been tested for the COVID and we're negative. We wear our masks, and we're doing everything else, and we've been okay thus far.... This mask thing is like - it's like it's been drummed in our heads now. So I wear my mask, and the kids wear their masks. And I feel a little bit safer doing those methods.

Patricia's grandmother and cousin were both hospitalized with COVID-19, and her grandmother now requires an oxygen tank. In light of those experiences, Patricia worried that she or her children might get COVID-19. Yet, she concluded that her grandmother and cousin, who she called "highrisk patients," likely experienced those outcomes because they were "older" and "overweight," which may have made their "immune systems weaker." By contrast, and like other mothers in this group (who were disproportionately Democrats/Democrat-leaning) Patricia described feeling as though she could control her family's risks of COVID-19 by having everyone wear masks, which she saw as "safer" than vaccines. 
A few mothers in this last group did not express concerns and instead actively endorsed both school-required immunizations and school mask mandates. Lydia (white, Master's degree, strong Democrat, educational consultant, mother of two young children), for example, "strongly agreed" that schools should require COVID-19 immunizations for students and also "strongly disagreed" that schools should make masks optional. With respect to vaccines, she explained:

I really trust that the scientists developing these vaccines would not say to take it when it's really not safe. I think that's why they're not out there vaccinating children now without having tested them. I mean, they're obviously not doing that. They're waiting until they do [test them]. So, I completely trust that when it's ready for children, it will be released and then we'll sign up.

Similarly, and explaining her position on masks, Lydia explained:

I work part-time [for the local school district], and I do some in-person testing with students. I'm very concerned when I go into schools that they always wear a mask. I always make sure the students I'm around are wearing their mask correctly. And they're required to wear it, but students sometimes need reminders.

One mother Lauren (white, Doctoral degree, Independent near Democrat, office administrator, mother a toddler and a preschooler) even said: "If there is a clinical trial for my kids, I would certainly enroll them in hopes that they are in the treatment group and not the placebo group." As these quotes illustrate, some mothers not only do not oppose school-based public health initiatives but also actively support those initiatives, instead.

\section{Discussion}

This study uses evidence from a novel mixed-methods study to examine whether, despite their tendency to follow medical recommendations (Courtenay 2000; Courtenay et al. 2002; Denton and Walters 1999; DiMatteo 2004; Read and Gorman 2010), women may be disproportionately likely to oppose some new public health initiatives. Consistent with our expectations, we find that mothers are significantly more likely than other parents to oppose school-required immunizations against COVID-19 but significantly less likely than other parents to oppose school mask mandates. Compared to other parents, mothers are also significantly more likely to report that they do not intend to vaccinate their children against COVID-19. Our qualitative data link these patterns to mothers' beliefs about whether they can control the risks associated with new medical innovations. Thus, we conclude that the gendered pressures mothers face as family health managers lead them, on the one hand, to disproportionately support new public health initiatives they perceive as useful for controlling risks to their children's health and, on the other hand, to disproportionately oppose new initiatives they perceive as entailing uncontrollable risks.

Building on work by Jennifer Reich (2020), Kevin Estep and Pierce Greenberg (2020), and Elisa J. Sobo and colleagues (2016), these findings highlight the consequences of our consumeristic, individualistic medical system, and they help to clarify and quantify the gendered impact of that system on women and mothers. As family health managers, mothers actively work to control their children's exposure to health risks (Burton-Jeangros 2011; Estep and Greenberg 2020; Mackendrick 
2014; Reich 2014, 2016b, 2016a, 2020b, 2020a; Sobo et al. 2016; Umamaheswar and Tan 2020; Waggoner 2017). In the context of politicized misinformation about COVID-19 (Loomba et al. 2001), some mothers perceive themselves as more able to control their children's risks of severe complications from the virus than their children's perceived risks of side effects from the COVID19 vaccine. Thus, these mothers oppose school-required immunizations (and plan to avoid or delay vaccinating their children) as a way to control their children's exposure to those perceived risks. Meanwhile, some of these mothers perceive masks as a useful tool for controlling their children's risk of exposure to COVID-19, so they do not oppose school mask mandates, even while they oppose school-required immunizations against COVID-19.

Taken together, these findings suggest that, in the context of a consumeristic/individualistic medical system, exposure to misinformation about new medical innovations can lead large numbers of women-roughly a third of U.S. mothers and nearly half of white Republican mothers-to oppose new public health initiatives like school-required vaccines. This opposition, in turn, can exist even among mothers who have traditionally followed childhood vaccine protocols. These findings are consistent with research showing that women may be more susceptible than men to health-related misinformation because of their trust of informal sources of medical information, such as social media (Freed et al. 2011). They are also consistent with research showing that parents may be increasingly adopting an individualistic approach to medicine, where they opt children strategically into and out of recommended medical care (Estep and Greenberg 2020; Reich 2020a).

These findings also have serious implications for the success of school-based public health initiatives aimed at curbing the spread of COVID-19 and other serious diseases. Given the role that mothers and especially white mothers play in influencing school policy (Horvat et al. 2003; Lareau and Horvat 1999; Lareau and Muñoz 2012; Lareau et al. 2018; Lewis-McCoy 2014; Posey-Maddox 2014; Sobo 2015), mothers who oppose school-required immunizations against COVID-19 and school mask mandates may be particularly influential in shaping schools' decisions about whether to institute these protections for students and staff. This seems especially likely given the clustering of opposition within particular subgroups of mothers. As research has shown, that clustering not only gives parents more power in influencing schools' engagement in public health initiatives but also increases the public health risk for people in those communities and schools (Estep and Greenberg 2020; Sobo 2015; Wang et al. 2014).

Furthermore, and even if parents are unsuccessful in resisting the implementation of school immunization requirements and mask mandates for COVID-19, they may still be successful in opting their own children out of those requirements. This would be consistent with research showing that parents (and especially white mothers) are often successful in exempting their children from normal school rules (Calarco 2020; Diekema 2014; Estep and Greenberg 2020; Lewis and Diamond 2015; Yang et al. 2015). If mothers who oppose school-required immunizations against COVID-19 or school mask mandates are ultimately successful in this opposition, it could limit the effectiveness of these initiatives and encourage the further spread of COVID-19 (Estep and Greenberg 2020; Sobo 2016). This is troubling given that new variants of COVID-19 may necessitate the development of new COVID-19 vaccines each year and may also require the ongoing use of masks during peak transmission times (CDC 2021). 
Ultimately, this study may portend a growing tide of opposition to childhood vaccines and schoolbased public health initiatives more generally. One quarter of all parents in our national sample (and nearly half_-45\%—of white Republican parents) opposed school-required immunizations against COVID-19). One quarter (and roughly one third-32\%—of white Republican parents) also opposed school mask mandates. This is a substantial portion of the population of parents-greater than the $17 \%$ of U.S. parents who reported in a 2017 survey that they opposed school-required immunizations against measles, mumps, and rubella (Funk 2017). Furthermore, and as our interviews revealed, opposition to school-required immunizations and school mask requirements exists even among parents who have traditionally followed traditional vaccine protocols. This could suggest that the stigma around vaccine refusal (Carpiano and Fitz 2017) may be weakening in the wake of COVID-19. That declining stigma could promote the further sharing of medical misinformation on social media and in social networks, which could lead parents who are hesitant about masks or vaccines to question other public health initiatives (Carpiano and Chi 2018). Essentially, the rise of consumerism in medicine (Reich 2020a; Timmermans and Oh 2010), coupled with the widespread proliferation of misinformation (Loomba et al. 2021; Wardle and Singerman 2021), may be leading to a crisis of confidence in public health-one that puts us all at greater risk.

\section{References}

AP-NORC. 2021. "Safety Concerns Remain Main Driver of Vaccine Hesitancy." Associated Press; National Opinion Research Council.

Berezin, Mabel, and Alicia Eads. 2016. "Risk Is for the Rich? Childhood Vaccination Resistance and a Culture of Health." Social Science \& Medicine 165:233-45.

Bhasin, Tavishi, Charity Butcher, Elizabeth Gordon, Maia Hallward, and Rebecca LeFebvre. 2020. "Does Karen Wear a Mask? The Gendering of COVID-19 Masking Rhetoric." International Journal of Sociology and Social Policy 40(9/10):929-37.

Blume, Stuart. 2006. “Anti-Vaccination Movements and Their Interpretations.” Social Science \& Medicine 62(3):628-42.

Borghans, Lex, James J. Heckman, Bart H. H. Golsteyn, and Huub Meijers. 2009. “Gender Differences in Risk Aversion and Ambiguity Aversion." Journal of the European Economic Association 7(2-3):649-58.

Bruine de Bruin, Wändi, Htay-Wah Saw, and Dana P. Goldman. 2020. "Political Polarization in US Residents' COVID-19 Risk Perceptions, Policy Preferences, and Protective Behaviors." Journal of Risk and Uncertainty 61(2):177-94.

Burton-Jeangros, Claudine. 2011. "Surveillance of Risks in Everyday Life: The Agency of Pregnant Women and Its Limitations." Social Theory \& Health 9(4):419-36.

Calarco, Jessica McCrory. 2020. “Avoiding Us versus Them: How Schools’ Dependence on Privileged 'Helicopter' Parents Influences Enforcement of Rules." American Sociological Review 85(2):223-46. 
Callaghan, Timothy, Ali Moghtaderi, Jennifer A. Lueck, Peter Hotez, Ulrich Strych, Avi Dor, Erika Franklin Fowler, and Matthew Motta. 2021. "Correlates and Disparities of Intention to Vaccinate against COVID-19.” Social Science \& Medicine (1982) 272:113638.

Callaway, Ewen, and Heidi Ledford. 2021. "How to Redesign COVID Vaccines so They Protect against Variants.” Nature 590(7844):15-16.

Calvillo, Dustin P., Bryan J. Ross, Ryan J. B. Garcia, Thomas J. Smelter, and Abraham M. Rutchick. 2020. "Political Ideology Predicts Perceptions of the Threat of COVID-19 (and Susceptibility to Fake News About It)." Social Psychological and Personality Science 11(8):1119-28.

Carpiano, Richard M., and Donald L. Chi. 2018. "Parents' Attitudes towards Topical Fluoride and Vaccines for Children: Are These Distinct or Overlapping Phenomena?” Preventive Medicine Reports 10:123-28.

Carpiano, Richard M., and Nicholas S. Fitz. 2017. "Public Attitudes toward Child Undervaccination: A Randomized Experiment on Evaluations, Stigmatizing Orientations, and Support for Policies." Social Science \& Medicine 185:127-36.

Cassino, Dan, and Yasemin Besen-Cassino. 2020. "Of Masks and Men? Gender, Sex, and Protective Measures during COVID-19.” Politics \& Gender 16(4):1052-62.

CDC. 2021. "About Variants of the Virus That Causes COVID-19.” Centers for Disease Control and Prevention.

Cheng, Kar Keung, Tai Hing Lam, and Chi Chiu Leung. 2020. "Wearing Face Masks in the Community during the COVID-19 Pandemic: Altruism and Solidarity." The Lancet.

Clarke, Adele E., Janet K. Shim, Laura Mamo, Jennifer Ruth Fosket, and Jennifer R. Fishman. 2003. "Biomedicalization: Technoscientific Transformations of Health, Illness, and U.S. Biomedicine." American Sociological Review 68(2):161-94.

Colgrove, James. 2010. “The Coercive Hand, the Beneficent Hand : What the History of Compulsory Vaccination Can Tell Us about HPV Vaccine Mandates." in Three shots at prevention: the HPV vaccine and the politics of medicine's simple solutions, edited by K. Wailoo. Johns Hopkins University Press.

Colgrove, James. 2016. "Vaccine Refusal Revisited — The Limits of Public Health Persuasion and Coercion.” New England Journal of Medicine 375:1316-1317.

Courtenay, Will H. 2000. “Constructions of Masculinity and Their Influence on Men's Well-Being: A Theory of Gender and Health.” Social Science \& Medicine 50(10):1385-1401.

Courtenay, Will H., Donald R. Mccreary, and Joseph R. Merighi. 2002. "Gender and Ethnic Differences in Health Beliefs and Behaviors." Journal of Health Psychology 7(3):219-31.

Cucchiara, Maia Bloomfield. 2013. Marketing Schools, Marketing Cities. University of Chicago Press. 
Denton, Margaret, and Vivienne Walters. 1999. "Gender Differences in Structural and Behavioral Determinants of Health: An Analysis of the Social Production of Health.” Social Science \& Medicine 48(9):1221-35.

Diamond, Dan. 2021. "Meet the GOP Voters Who Could Decide Whether the U.S. Reaches Herd Immunity." W ashington Post.

Diekema, Douglas S. 2014. "Personal Belief Exemptions From School Vaccination Requirements." Annual Review of Public Health 35:275-92.

DiMatteo, M. Robin. 2004. 'Variations in Patients' Adherence to Medical Recommendations: A Quantitative Review of 50 Years of Research.” Medical Care 42(3):200-209.

Dubé, Eve, Maryline Vivion, and Noni E. MacDonald. 2015. "Vaccine Hesitancy, Vaccine Refusal and the Anti-Vaccine Movement: Influence, Impact and Implications." Expert Review of Vaccines 14(1):99-117.

EdWeek. 2021. “COVID-19 Vaccines and Schools: Your Questions Answered,” Education Week.

Eikenberry, Steffen E., et al. 2020. "To Mask or Not to Mask: Modeling the Potential for Face Mask Use by the General Public to Curtail the COVID-19 Pandemic.” Infectious Disease Modelling 5:293-308.

Elliott, Sinikka, and Sarah Bowen. 2018. "Defending Motherhood: Morality, Responsibility, and Double Binds in Feeding Children.” Journal of Marriage and Family 80(2):499-520.

Estep, Kevin, and Pierce Greenberg. 2020. "Opting Out: Individualism and Vaccine Refusal in Pockets of Socioeconomic Homogeneity.” American Sociological Review 85(6):957-91.

Freed, Gary L., Sarah J. Clark, Amy T. Butchart, Dianne C. Singer, and Matthew M. Davis. 2011. "Sources and Perceived Credibility of Vaccine-Safety Information for Parents." Pediatrics 127(1):S107.

Funk, Cary, and Alec Tyson. 2020. Intent to Get a COVID-19 Vaccine Rises to 60\% as Confidence in Research and Development Process Increases. Pew Research Center.

Funk, Gary. 2017. "Parents of Young Children Are More 'Vaccine Hesitant.”' Pew Research Center.

Gage-Bouchard, Elizabeth A. 2017a. "Culture, Styles of Institutional Interactions, and Inequalities in Healthcare Experiences." Journal of Health and Social Behavior 58(2):147-65.

Gage-Bouchard, Elizabeth A. 2017b. "Social Support, Flexible Resources, and Health Care Navigation.” Social Science \& Medicine 190:111-18..

Gard, Michael, and Carolyn Pluim. 2014. Schools and Public Health: Past, Present, Future. Lexington Books.

Glied, Sherry, and Adriana Lleras-Muney. 2008. "Technological Innovation and Inequality in Health." Demography 45(3):741-61.. 
Haischer, Michael H. et al. 2020. "Who Is Wearing a Mask? Gender-, Age-, and Location-Related Differences during the COVID-19 Pandemic.” MedRxiv 2020.

Hart, P. Sol, Sedona Chinn, and Stuart Soroka. 2020. "Politicization and Polarization in COVID-19 News Coverage.” Science Communication 42(5):679-97.

Hearne, Brittany N., and Michael D. Niño. 2021. "Understanding How Race, Ethnicity, and Gender Shape Mask-Wearing Adherence During the COVID-19 Pandemic: Evidence from the COVID Impact Survey." Journal of Racial and Ethnic Health Disparities.

Horvat, Erin McNamara, Elliot B. Weininger, and Annette Lareau. 2003. "From Social Ties to Social Capital: Class Differences in the Relations Between Schools and Parent Networks." American Educational Research Journal 40(2):319-51.

Kahan, Dan M. 2013. “A Risky Science Communication Environment for Vaccines.” Science 342(6154):53-54.

Kao, Carol M., Walter A. Orenstein, and Evan J. Anderson. 2021. "The Importance of Advancing Severe Acute Respiratory Syndrome Coronavirus 2 Vaccines in Children.” Clinical Infectious Diseases 72(3):515-18.

Khazan, Olga. 2020. "How a Bizarre Claim About Masks Has Lived on for Months." The Atlantic, October 9.

Kim, Jerome H., Florian Marks, and John D. Clemens. 2021. "Looking beyond COVID-19 Vaccine Phase 3 Trials." Nature Medicine 27(2):205-11.

Kramer, Stephanie. 2020. "More Americans Say They Are Regularly Wearing Masks in Stores and Other Businesses." Pew Research Center.

Lakshmanan, Rekha, and Jason Sabo. 2020. "Lessons from the Front Line: Advocating for Vaccine Policies at the Texas Capitol During Turbulent Times." Journal of Applied Research on Children: Informing Policy for Children at Risk 10(2).

Lareau, Annette. 2011. Unequal Childhoods. Berkeley, CA: University of California Press.

Lareau, Annette, and Erin McNamara Horvat. 1999. "Moments of Social Inclusion and Exclusion Race, Class, and Cultural Capital in Family-School Relationships." Sociology of Education 72(1):37-53.

Lareau, Annette, and Vanessa Lopes Muñoz. 2012. “'You're Not Going to Call the Shots': Structural Conflicts between the Principal and the PTO at a Suburban Public Elementary School." Sociology of Education 85(3):201-18.

Lareau, Annette, Elliot Weininger, and Amanda Cox. 2018. "Parental Challenges to Organizational Authority in an Elite School District: The Role of Cultural, Social, and Symbolic Capital." Teachers College Record 120(1). 
Laws, Rebecca L. et al. 2021. "Symptoms and Transmission of SARS-CoV-2 Among Children Utah and Wisconsin, March-May 2020.” Pediatrics 147(1).

Lewis, Amanda E., and John B. Diamond. 2015. Despite the Best Intentions: How Racial Inequality Thrives in Good Schools. New York: Oxford University Press.

Lewis-McCoy, R. L'Heureux. 2014. Inequality in the Promised Land: Race, Resources, and Suburban Schooling. Palo Alto, CA: Stanford University Press.

Lindley, Megan C., Lynda Boyer-Chu, Daniel B. Fishbein, Maureen Kolasa, Amy B. Middleman, Thad Wilson, JoEllen Wolicki, and Susan Wooley. 2008. "The Role of Schools in Strengthening Delivery of New Adolescent Vaccinations.” Pediatrics 121(Supplement 1):S4654.

Logan, Nicola S., and Bernard Gilmartin. 2004. "School Vision Screening, Ages 5-16 Years: The Evidence-Base for Content, Provision and Efficacy." Ophthalmic and Physiological Optics 24(6):481-92.

Loomba, Sahil, Alexandre de Figueiredo, Simon J. Piatek, Kristen de Graaf, and Heidi J. Larson. 2021. "Measuring the Impact of COVID-19 Vaccine Misinformation on Vaccination Intent in the UK and USA." Nature Human Behaviour 1-12.

Ludvigsson, Jonas F. 2020. "Systematic Review of COVID-19 in Children Shows Milder Cases and a Better Prognosis than Adults." Acta Paediatrica 109(6):1088-95.

Luker, Kristin. 2007. When Sex Goes to School: Warring Views on Sex--and Sex Education--Since the Sixties. W. W. Norton \& Company.

Lutfey, Karen, and Jeremy Freese. 2005. "Toward Some Fundamentals of Fundamental Causality: Socioeconomic Status and Health in the Routine Clinic Visit for Diabetes." American Journal of Sociology 110(5):1326-72.

Mackendrick, Norah. 2014. "More Work for Mother: Chemical Body Burdens as a Maternal Responsibility." Gender \& Society 28(5):705-28.

Miles, Matthew B., and A. Michael Huberman. 1994. Qualitative Data Analysis: An Expanded Sourcebook. SAGE.

Murray, Brittany, Thurston Domina, Linda Renzulli, and Rebecca Boylan. 2019. "Civil Society Goes to School: Parent-Teacher Associations and the Equality of Educational Opportunity." RSF: The Russell Sage Foundation Journal of the Social Sciences 5(3):41-63.

NCSL. 2021. "States With Religious and Philosophical Exemptions From School Immunization Requirements." National Conference of State Legislatures.

North, Anna L., and Linda M. Niccolai. 2016. "Human Papillomavirus Vaccination Requirements in US Schools: Recommendations for Moving Forward." American Journal of Public Health 106(10):1765-70. 
Palmer, Carl L., and Rolfe D. Peterson. 2020. “Toxic Mask-Ulinity: The Link between Masculine Toughness and Affective Reactions to Mask Wearing in the COVID-19 Era." Politics \& Gender 16(4):1044-51.

Polack, Fernando P. et al. 2020. "Safety and Efficacy of the BNT162b2 MRNA Covid-19 Vaccine." New England Journal of Medicine 383(27):2603-15..

Posey-Maddox, Linn. 2014. When Middle-Class Parents Choose Urban Schools: Class, Race, and the Challenge of Equity in Public Education. University of Chicago Press.

Pulido, Cristina M., Beatriz Villarejo-Carballido, Gisela Redondo-Sama, and Aitor Gómez. 2020. "COVID-19 Infodemic: More Retweets for Science-Based Information on Coronavirus than for False Information.” International Sociology 35(4):377-92.

Rajmil, Luis. 2020. "Role of Children in the Transmission of the COVID-19 Pandemic: A Rapid Scoping Review.” BMJ Paediatrics Open 4(1).

Ranji, Usha, and Alina Salganicoff. 2014. Balancing on Shaky Ground: Women, Work, and Family Health. Kaiser Family Foundation.

Read, Jen'nan Ghazal, and Bridget K. Gorman. 2010. “Gender and Health Inequalities.” Annual Review of Sociology 36:371-86.

Reich, Jennifer A. 2014. "Neoliberal Mothering and Vaccine Refusal: Imagined Gated Communities and the Privilege of Choice." Gender \& Society 28(5):679-704.

Reich, Jennifer A. 2016a. Calling the Shots: Why Parents Reject Vaccines. New York, NY: NYU Press.

Reich, Jennifer A. 2016b. "Of Natural Bodies and Antibodies: Parents' Vaccine Refusal and the Dichotomies of Natural and Artificial." Social Science \& Medicine 157:103-10.

Reich, Jennifer A. 2020a. "Vaccine Refusal and Pharmaceutical Acquiescence: Parental Control and Ambivalence in Managing Children's Health.” American Sociological Review 85(1):106-27.

Reich, Jennifer A. 2020b. “"We Are Fierce, Independent Thinkers and Intelligent': Social Capital and Stigma Management among Mothers Who Refuse Vaccines." Social Science \& Medicine $257: 112015$.

Rojas, Rick, James Dobbins, and Maria Jimenez Moya. 2021. “With Texas' Mask Mandate Over, Workers Worry About Encroaching Virus.” The New York Times, March 10.

Rosen, Allison B., Jerry S. Tsai, and Stephen M. Downs. 2003. "Variations in Risk Attitude across Race, Gender, and Education.” Medical Decision Making 23(6):511-17.

Rothgerber, Hank, Thomas Wilson, Davis Whaley, Daniel L. Rosenfeld, Michael Humphrey, Allie Moore, and Allison Bihl. 2020. "Politicizing the COVID-19 Pandemic: Ideological Differences in Adherence to Social Distancing." 
Seymour, Brittany, Rebekah Getman, Avinash Saraf, Lily H. Zhang, and Elsbeth Kalenderian. 2015. "When Advocacy Obscures Accuracy Online: Digital Pandemics of Public Health Misinformation Through an Antifluoride Case Study." American Journal of Public Health 105(3):517-23.

Sobo, Elisa J. 2015. "Social Cultivation of Vaccine Refusal and Delay among Waldorf (Steiner) School Parents: Social Cultivation of Vaccine Refusal.” Medical Anthropology Quarterly 29(3):381-99.

Sobo, Elisa J. 2016. "What Is Herd Immunity, and How Does It Relate to Pediatric Vaccination Uptake? US Parent Perspectives.” Social Science \& Medicine 165:187-95.

Sobo, Elisa J., Arianna Huhn, Autumn Sannwald, and Lori Thurman. 2016. "Information Curation among Vaccine Cautious Parents: Web 2.0, Pinterest Thinking, and Pediatric Vaccination Choice." Medical Anthropology 35(6):529-46..

Sparling, Phillip B., Neville Owen, Estelle V. Lambert, and William L. Haskell. 2000. "Promoting Physical Activity: The New Imperative for Public Health." Health Education Research 15(3):367-76.

Timmermans, Stefan, and Hyeyoung Oh. 2010. "The Continued Social Transformation of the Medical Profession.” Journal of Health and Social Behavior 51(1_suppl):S94-106.

Umamaheswar, Janani, and Catherine Tan. 2020. “Dad, Wash Your Hands': Gender, Care Work, and Attitudes toward Risk during the COVID-19 Pandemic," Socius. $10.1177 / 2378023120964376$

USDA. 2019. USD A Foods in Schools. United States Department of Agriculture.

Waggoner, Miranda R. 2017. The Zero Trimester. University of California Press.

Wardle, Claire, and Eric Singerman. 2021. “Too Little, Too Late: Social Media Companies’ Failure to Tackle Vaccine Misinformation Poses a Real Threat.” BMJ 372:n26.

Xiao, Xizhu, and Rachel Min Wong. 2020. "Vaccine Hesitancy and Perceived Behavioral Control: A Meta-Analysis.” Vaccine 38(33):5131-38.

Yang, Y. Tony, Paul L. Delamater, Timothy F. Leslie, and Michelle M. Mello. 2015. "Sociodemographic Predictors of Vaccination Exemptions on the Basis of Personal Belief in California." American Journal of Public Health 106(1):172-77. 
Table 1: Demographic characteristics of the ITD survey sample $(\mathrm{N}=1,946)$, with percent opposing schoolrequired immunizations against COVID-19 and school mask mandates

\begin{tabular}{|c|c|c|c|c|}
\hline & $\mathrm{N}$ & $\begin{array}{l}\text { Sample } \\
\%\end{array}$ & $\begin{array}{l}\text { School COVID-19 } \\
\text { Immunization } \\
\text { Requirements } \\
\text { (\% opposed) }\end{array}$ & $\begin{array}{l}\text { School Mask } \\
\text { Mandates } \\
(\% \text { opposed })\end{array}$ \\
\hline \multicolumn{5}{|l|}{ Dependent Variables } \\
\hline \multicolumn{5}{|l|}{$\begin{array}{l}\text { Opposition to School COVID-19 } \\
\text { Immunization Requirement }\end{array}$} \\
\hline Oppose & 545 & $26.8 \%$ & - & - \\
\hline Do not oppose & 1,401 & $73.2 \%$ & - & - \\
\hline \multicolumn{5}{|l|}{ Opposition to School Mask Mandate } \\
\hline Oppose & 516 & $25.1 \%$ & - & - \\
\hline Do not oppose & 1,430 & $74.8 \%$ & - & 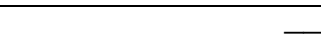 \\
\hline \multicolumn{5}{|l|}{ Respondent Characteristics } \\
\hline \multicolumn{5}{|l|}{ Gender Identity } \\
\hline Woman & 1,042 & $54.5 \%$ & $32.8 \%$ & $17.7 \%$ \\
\hline Man/ Nonbinary/Self-identified & 904 & $45.5 \%$ & $19.7 \%$ & $34.0 \%$ \\
\hline \multicolumn{5}{|l|}{ 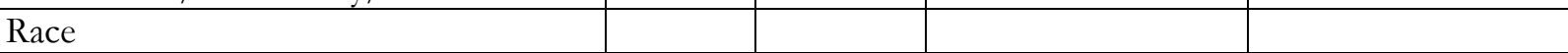 } \\
\hline White, Non-Hispanic & 1,079 & $57.3 \%$ & $28.7 \%$ & $28.4 \%$ \\
\hline Hispanic/Latino/a & 336 & $16.9 \%$ & $24.1 \%$ & $22.7 \%$ \\
\hline Black, Non-Hispanic & 218 & $11.1 \%$ & $33.0 \%$ & $21.7 \%$ \\
\hline $\begin{array}{r}\text { Other race/ethnicity, including Asian } \\
\text { American, Pacific Islander, Native } \\
\text { American, and Multiracial }\end{array}$ & 313 & $14.8 \%$ & $17.4 \%$ & $17.8 \%$ \\
\hline \multicolumn{5}{|l|}{ Education } \\
\hline Has Not Completed a BA Degree & 1,115 & $62.5 \%$ & $32.8 \%$ & $19.4 \%$ \\
\hline Has Completed a BA Degree & 500 & $22.7 \%$ & $19.5 \%$ & $25.8 \%$ \\
\hline $\begin{array}{r}\text { Has Completed an Advanced Degree } \\
\text { (e.g., MA, MD, JD, PhD) }\end{array}$ & 331 & $14.8 \%$ & $13.0 \%$ & $48.1 \%$ \\
\hline \multicolumn{5}{|l|}{ Family Income } \\
\hline$<\$ 25,000$ & 293 & $18.3 \%$ & $24.1 \%$ & $21.9 \%$ \\
\hline$\$ 25,000$ to $\$ 49,999$ & 388 & $18.8 \%$ & $40.0 \%$ & $17.7 \%$ \\
\hline$\$ 50,000$ to $\$ 74,999$ & 372 & $18.6 \%$ & $34.5 \%$ & $21.6 \%$ \\
\hline$\$ 75,000$ to $\$ 99,999$ & 290 & $15.1 \%$ & $22.0 \%$ & $24.8 \%$ \\
\hline$\$ 100,000+$ & 603 & $29.3 \%$ & $17.8 \%$ & $34.3 \%$ \\
\hline \multicolumn{5}{|l|}{ Partnership Status } \\
\hline Not married/cohabitating & 434 & $18.8 \%$ & $31.0 \%$ & $16.9 \%$ \\
\hline Married/cohabitating & 1,512 & $81.2 \%$ & $25.9 \%$ & $27.0 \%$ \\
\hline \multicolumn{5}{|l|}{ Pre-Pandemic Employment } \\
\hline Full time & 1,320 & $64.6 \%$ & $24.7 \%$ & $29.7 \%$ \\
\hline Part time & 189 & $10.8 \%$ & $30.3 \%$ & $19.2 \%$ \\
\hline Not working & 437 & $24.7 \%$ & $31.0 \%$ & $15.7 \%$ \\
\hline \multicolumn{5}{|l|}{ Political Party Identification } \\
\hline Democrat/Leans Democrat & 980 & $48.6 \%$ & $16.4 \%$ & $25.0 \%$ \\
\hline Independent/Other Party & 399 & $22.0 \%$ & $27.0 \%$ & $19.0 \%$ \\
\hline Republican/Leans Republican & 567 & $29.4 \%$ & $43.9 \%$ & $30.0 \%$ \\
\hline Region & & & & \\
\hline
\end{tabular}




\begin{tabular}{|c|c|c|c|c|}
\hline Northeast & 336 & $16.8 \%$ & $18.4 \%$ & $29.4 \%$ \\
\hline Midwest & 462 & $24.3 \%$ & $27.9 \%$ & $23.4 \%$ \\
\hline South & 719 & $36.7 \%$ & $30.9 \%$ & $25.9 \%$ \\
\hline West & 429 & $22.2 \%$ & $25.4 \%$ & $22.6 \%$ \\
\hline \multicolumn{5}{|l|}{ R COVID-19 Illness Experience } \\
\hline Has not had COVID & 1,406 & $73.5 \%$ & $24.9 \%$ & $21.7 \%$ \\
\hline Has had COVID & 540 & $26.6 \%$ & $32.3 \%$ & $34.5 \%$ \\
\hline \multicolumn{5}{|l|}{ Network COVID Impact } \\
\hline None & 946 & $52.2 \%$ & $25.3 \%$ & $25.3 \%$ \\
\hline At least one person & 1,000 & $47.8 \%$ & $28.5 \%$ & $25.0 \%$ \\
\hline \multicolumn{5}{|l|}{ Mediating Variables } \\
\hline \multicolumn{5}{|l|}{$\mathrm{R}$ intent to receive COVID-19 vaccine } \\
\hline Not very/somewhat likely & 1,092 & $57.9 \%$ & $42.1 \%$ & $18.7 \%$ \\
\hline Very/somewhat likely & 854 & $42.1 \%$ & $5.9 \%$ & $34.0 \%$ \\
\hline \multicolumn{5}{|l|}{$\begin{array}{l}\mathrm{R} \text { intent to give child COVID-19 } \\
\text { vaccine }\end{array}$} \\
\hline Not very/somewhat likely & 1,128 & $59.7 \%$ & $40.3 \%$ & $20.9 \%$ \\
\hline Very/somewhat likely & 818 & $40.3 \%$ & $6.8 \%$ & $31.5 \%$ \\
\hline \multicolumn{5}{|l|}{$\mathrm{R}$ wore mask last outing } \\
\hline Not at all/part of the time & 639 & $32.2 \%$ & $37.6 \%$ & $27.8 \%$ \\
\hline The whole time & 1,307 & $67.8 \%$ & $21.7 \%$ & $23.9 \%$ \\
\hline \multicolumn{5}{|l|}{ Child wore mask last outing } \\
\hline Not at all/part of the time & 630 & $31.3 \%$ & $37.2 \%$ & $26.5 \%$ \\
\hline The whole time & 1,316 & $68.7 \%$ & $22.1 \%$ & $24.5 \%$ \\
\hline
\end{tabular}


Table 2: Demographic characteristics of mothers who completed a PPS interview and the PPS Wave 2 survey $(\mathrm{N}=64)$

\begin{tabular}{ll}
\hline & Sample \\
\hline White Mothers & 55 \\
Mothers of Color & 9 \\
& \\
Married & 57 \\
Cohabiting & 3 \\
Separated/Divorced/Not Married & 4 \\
& \\
Has not completed a Bachelor's Degree & 17 \\
Completed a Bachelor's Degree & 22 \\
Completed an Advanced Degree & 25 \\
& \\
Employed full time/Self-employed (Feb 2020) & 27 \\
Employed part time (Feb 2020) & 14 \\
Full-time parent (Feb 2020) & 23 \\
& \\
Under \$25,000 (2020) & 3 \\
\$25,000 to \$49,999 (2020) & 15 \\
\$50,000 to \$74,999 (2020) & 12 \\
\$75,000 to \$99,999 (2020) & 15 \\
\$100,000 to \$149,999 (2020) & 12 \\
\$150,000 or more (2020) & 5 \\
Not answered & 2 \\
Democrat/Democrat-leaning & \\
Independent/Other party & 35 \\
Republican/Republican-leaning & 9 \\
\hline
\end{tabular}


Table 3: Parents' Likelihood of Opposing School-Required Immunizations against COVID-19 and School Mask Mandates (Odds Ratios)

\begin{tabular}{|c|c|c|c|c|c|c|}
\hline & $\begin{array}{c}\text { M1 } \\
\text { Oppose School } \\
\text { Vaccine Mandate }\end{array}$ & $\begin{array}{c}\mathrm{M} 2 \\
+\mathrm{R} \text { Vaccine } \\
\text { Intentions }\end{array}$ & $\begin{array}{c}\text { M3 } \\
+ \text { Child Vaccine } \\
\text { Intentions }\end{array}$ & $\begin{array}{c}\text { M4 } \\
\text { Oppose School } \\
\text { Mask } \\
\text { Mandate }\end{array}$ & $\begin{array}{c}\text { M5 } \\
+ \text { R Mask } \\
\text { Wearing }\end{array}$ & $\begin{array}{c}\text { M6 } \\
+ \text { Child Mask } \\
\text { Wearing }\end{array}$ \\
\hline main & & & & & & \\
\hline Gender (Woman) & $\begin{array}{l}1.62^{* *} \\
(0.25)\end{array}$ & $\begin{array}{l}1.48^{*} \\
(0.24)\end{array}$ & $\begin{array}{c}1.34 \\
(0.22)\end{array}$ & $\begin{array}{l}0.60^{* * *} \\
(0.09)\end{array}$ & $\begin{array}{l}0.59^{* * *} \\
(0.08)\end{array}$ & $\begin{array}{l}0.59^{* * *} \\
(0.08)\end{array}$ \\
\hline Education & & & & & & \\
\hline$<\mathrm{BA}$ & $\begin{array}{l}1.54^{* *} \\
(0.24)\end{array}$ & $\begin{array}{c}1.28 \\
(0.22)\end{array}$ & $\begin{array}{c}1.31 \\
(0.22)\end{array}$ & $\begin{array}{c}0.79 \\
(0.12)\end{array}$ & $\begin{array}{c}0.77 \\
(0.12)\end{array}$ & $\begin{array}{c}0.78 \\
(0.12)\end{array}$ \\
\hline Advanced Degree & $\begin{array}{c}0.81 \\
(0.18)\end{array}$ & $\begin{array}{c}1.10 \\
(0.27)\end{array}$ & $\begin{array}{l}1.04 \\
(0.25)\end{array}$ & $\begin{array}{l}2.14^{* * *} \\
(0.35)\end{array}$ & $\begin{array}{l}2.20^{* * *} \\
(0.37)\end{array}$ & $\begin{array}{l}2.17^{* * *} \\
(0.36)\end{array}$ \\
\hline Hispanic/Latino & $\begin{array}{c}0.80 \\
(0.18)\end{array}$ & $\begin{array}{c}0.74 \\
(0.18)\end{array}$ & $\begin{array}{c}0.69 \\
(0.17)\end{array}$ & $\begin{array}{c}0.98 \\
(0.22)\end{array}$ & $\begin{array}{c}0.97 \\
(0.22)\end{array}$ & $\begin{array}{c}0.97 \\
(0.22)\end{array}$ \\
\hline Black & $\begin{array}{l}1.91^{* *} \\
(0.43)\end{array}$ & $\begin{array}{l}1.53 \\
(0.35)\end{array}$ & $\begin{array}{l}1.57^{*} \\
(0.36)\end{array}$ & $\begin{array}{l}1.04 \\
(0.24)\end{array}$ & $\begin{array}{l}1.04 \\
(0.24)\end{array}$ & $\begin{array}{l}1.04 \\
(0.24)\end{array}$ \\
\hline Other race & $\begin{array}{l}0.56^{* *} \\
(0.12)\end{array}$ & $\begin{array}{l}0.54^{* *} \\
(0.13)\end{array}$ & $\begin{array}{l}0.55^{* *} \\
(0.13)\end{array}$ & $\begin{array}{l}0.63^{*} \\
(0.12)\end{array}$ & $\begin{array}{l}0.64^{*} \\
(0.12)\end{array}$ & $\begin{array}{l}0.64^{*} \\
(0.12)\end{array}$ \\
\hline $\begin{array}{l}\text { Income } \\
\\
\text { Less than } \$ 25,000\end{array}$ & $\begin{array}{c}1.04 \\
(0.30)\end{array}$ & $\begin{array}{c}0.83 \\
(0.25)\end{array}$ & $\begin{array}{c}0.85 \\
(0.25)\end{array}$ & $\begin{array}{c}1.19 \\
(0.30)\end{array}$ & $\begin{array}{c}1.24 \\
(0.32)\end{array}$ & $\begin{array}{c}1.21 \\
(0.32)\end{array}$ \\
\hline$\$ 25,000$ to $\$ 49,999$ & $\begin{array}{l}2.02^{* * *} \\
(0.42)\end{array}$ & $\begin{array}{l}1.58^{*} \\
(0.35)\end{array}$ & $\begin{array}{l}1.69^{*} \\
(0.37)\end{array}$ & $\begin{array}{c}0.84 \\
(0.18)\end{array}$ & $\begin{array}{c}0.84 \\
(0.18)\end{array}$ & $\begin{array}{c}0.84 \\
(0.18)\end{array}$ \\
\hline$\$ 50,000$ to $\$ 74,999$ & $\begin{array}{l}1.80^{* *} \\
(0.34)\end{array}$ & $\begin{array}{l}1.55^{*} \\
(0.32)\end{array}$ & $\begin{array}{l}1.60^{*} \\
(0.33)\end{array}$ & $\begin{array}{c}0.94 \\
(0.17)\end{array}$ & $\begin{array}{c}0.93 \\
(0.17)\end{array}$ & $\begin{array}{c}0.94 \\
(0.17)\end{array}$ \\
\hline$\$ 75,000$ to $\$ 99,999$ & $\begin{array}{l}1.10 \\
(0.22)\end{array}$ & $\begin{array}{l}0.99 \\
(0.21)\end{array}$ & $\begin{array}{c}1.02 \\
(0.22)\end{array}$ & $\begin{array}{c}0.87 \\
(0.16)\end{array}$ & $\begin{array}{c}0.87 \\
(0.16)\end{array}$ & $\begin{array}{c}0.88 \\
(0.16)\end{array}$ \\
\hline Married/cohabiting & 0.92 & 0.94 & 0.83 & 151 & $156^{*}$ & 153 \\
\hline $\begin{array}{l}\text { Pandemic employment } \\
\text { Part time }\end{array}$ & $\begin{array}{c}(0.17) \\
1.14 \\
(0.25)\end{array}$ & $\begin{array}{c}(0.19) \\
1.06 \\
(0.25)\end{array}$ & $\begin{array}{c}(0.17) \\
1.12 \\
(0.26)\end{array}$ & $\begin{array}{c}(0.34) \\
0.95 \\
(0.28)\end{array}$ & $\begin{array}{c}(0.35) \\
0.94 \\
(0.27)\end{array}$ & $\begin{array}{c}(0.34) \\
0.95 \\
(0.28)\end{array}$ \\
\hline Not working & 0.84 & 0.80 & 0.86 & 0.76 & 0.77 & 0.77 \\
\hline
\end{tabular}




\begin{tabular}{|c|c|c|c|c|c|c|}
\hline & $(0.14)$ & $(0.15)$ & $(0.15)$ & $(0.15)$ & $(0.15)$ & $(0.15)$ \\
\hline Region & $\begin{array}{l}1.42^{*} \\
(0.24)\end{array}$ & $\begin{array}{l}1.43^{*} \\
(0.26)\end{array}$ & $\begin{array}{l}1.43^{*} \\
(0.26)\end{array}$ & $\begin{array}{l}1.87^{* * *} \\
(0.28)\end{array}$ & $\begin{array}{l}1.84^{* * *} \\
(0.28)\end{array}$ & $\begin{array}{l}1.86^{* * *} \\
(0.28)\end{array}$ \\
\hline \multicolumn{7}{|l|}{ Midwest } \\
\hline \multirow{3}{*}{ South } & 1.34 & 1.12 & 1.22 & 0.82 & 0.80 & 0.80 \\
\hline & $(0.27)$ & $(0.24)$ & $(0.26)$ & $(0.15)$ & $(0.15)$ & $(0.15)$ \\
\hline & 1.40 & 1.23 & 1.27 & 1.00 & 1.00 & 1.00 \\
\hline \multirow[t]{2}{*}{ West } & $(0.27)$ & $(0.25)$ & $(0.26)$ & $(0.18)$ & $(0.18)$ & $(0.18)$ \\
\hline & 1.39 & 1.30 & 1.33 & 0.90 & 0.91 & 0.90 \\
\hline \multirow[t]{2}{*}{ Network COVID impact } & $(0.29)$ & $(0.29)$ & $(0.30)$ & $(0.19)$ & $(0.19)$ & $(0.19)$ \\
\hline & 1.21 & $1.51^{* *}$ & $1.46^{*}$ & 0.87 & 0.86 & 0.87 \\
\hline \multirow{2}{*}{$\begin{array}{l}\text { Political affiliation } \\
\text { Independent/Other }\end{array}$} & $(0.17)$ & $(0.23)$ & $(0.22)$ & $(0.12)$ & $(0.12)$ & $(0.12)$ \\
\hline & $167^{* *}$ & 126 & 135 & 099 & 097 & 097 \\
\hline \multirow{2}{*}{ Repub/Lean Repub } & $(0.30)$ & $(0.25)$ & $(0.27)$ & $(0.21)$ & $(0.20)$ & $(0.20)$ \\
\hline & $4.30^{* * *}$ & $3.16^{* * *}$ & $3.32^{* * *}$ & $1.52^{* *}$ & $1.42^{*}$ & $1.45^{*}$ \\
\hline \multirow[t]{2}{*}{$\mathrm{R}$ likelihood to vacc. } & $(0.68)$ & $(0.54)$ & $(0.57)$ & $(0.24)$ & $(0.23)$ & $(0.23)$ \\
\hline & & $0.10^{* * *}$ & & & & \\
\hline \multirow[t]{2}{*}{ Likelihood to vacc child } & & $(0.02)$ & & & & \\
\hline & & & $0.13^{* * *}$ & & & \\
\hline \multirow{2}{*}{$\mathrm{R}$ mask wearing } & & & $(0.02)$ & & & \\
\hline & & & & & & \\
\hline Child mask wearing & & & & & $0.69^{*}$ & \\
\hline Whole time & & & & & & \\
\hline
\end{tabular}

\begin{tabular}{lc}
\hline Observations & 0.78 \\
\hline Exponentiated coefficients; $t$ statistics in parentheses & $(0.12)$ \\
\hline
\end{tabular}

${ }^{*} p<0.05,{ }^{* *} p<0.01,{ }^{* * *} p<0.001$ 
Appendix A: Key Survey and Interview Questions

Survey Questions

These questions were asked of parents who completed the ITD Survey and were also asked of mothers who completed the PPS Wave 2 Survey and Interviews.

1. How strongly do you agree or disagree with the following statement?

Schools in my town/ city should require students to receive a vaccination for coronavirus when a vaccination for children becomes publicly available.

( $1=$ Strongly Disagree, $2=$ Disagree, $3=$ Somewhat Disagree, 4=Neither Agree nor Disagree, $5=$ Somewhat Agree, $6=$ Agree, $7=$ Strongly Agree)

2. How strongly do you agree or disagree with the following statement? Students in my town/city should have the choice whether to wear masks to school.

(1=Strongly Disagree, 2=Disagree, 3=Somewhat Disagree, 4=Neither Agree nor Disagree, 5=Somewhat Agree, $6=$ Agree, $7=$ Strongly Agree)

3. How likely is it that you'll get your children vaccinated for COVID-19 vaccine when a vaccine is available for children?

(1=Very Unlikely, 2=Somewhat Unlikely, 3=A Little Unlikely, 4=Neither Unlikely Nor Likely, 5=A

Little Likely, 6=Somewhat Likely, $7=$ Very Likely)

4. How likely is it that you will get a COVID-19 vaccine when it becomes available?

(1=Very Unlikely, 2=Somewhat Unlikely, 3=A Little Unlikely, 4=Neither Unlikely Nor Likely, 5=A

Little Likely, 6=Somewhat Likely, $7=$ Very Likely)

5. The last time [your child] was around people other than those who live with you, did [your child] wear a mask or other face covering?

( $1=$ Yes, the whole time, $2=$ Yes, part of the time, $3=$ No, not at all $)$

6. The last time you were around people other than those who live with you, did you wear a mask or other face covering?

( $1=$ Yes, the whole time, $2=$ Yes, part of the time, $3=$ No, not at all)

Survey Questions

These questions were asked of mothers who completed the PPS Interviews.

Q. Where do you typically get information about the Coronavirus/COVID-19 these days?

Probes: Are there any other places where you go for information?

(e.g., specific friends or family members, social media like Facebook or Twitter, national news sources like CNN or New York Times or Fox News, local news sources like newspapers or TV news, health organizations like CDC or WHO, scientific journals or magazine) 
Q. When it comes to the virus, what are you hearing recently about how the virus is spreading and how dangerous it is?

Probes: What have you heard about how it spreads?

What have you heard about the symptoms of Coronavirus/COVID-19?

What have you heard about who is most affected by the virus?

Q. What have you heard about a vaccine for coronavirus/COVID-19?

Probes: What have you heard about when it will be available?

What have you heard about how safe it will be?

What have you heard about how well it works?

Q. What are your thoughts about the vaccine, generally?

Probes: Is there anything about it that worries you?

Is there anything that you're feeling hopeful about with the vaccine?

Q. What does your spouse/partner think about the vaccine?

Probes: Do you agree? Disagree?

Q. What do you think are the chances that you and your spouse/partner will get a vaccine for Coronavirus/COVID-19 when they're available to you?

Probes: Would you want to get vaccinated as soon as one is available to you, would you want to wait to get it, or not get it at all?

How will you make that decision?

Q. What do you think are the chances that your kids will get a vaccine for Coronavirus/COVID-19 when one is available for children?

Probes: Do you think they would get vaccinated right away, wait to get it, or not get it at all? How will your family make that decision?

Q. [If indicated would get vaccine] When you are able to get vaccinated, how do you think that would change things for you? Are there any things you would do differently?

Probes: Would you change how you are managing risks right now?

Are there activities that you don't do now, that you might do once vaccinated?

Would vaccination for you or any member of your family change your work arrangements (i.e. working from home vs. office)?

Would it change your plans for your child's education (i.e. in person vs. virtual learning, if it's optional) 
Q. [If Wave 1 Interview: Since we talked to you in May:] Has anyone in your household had the Coronavirus/COVID-19?

Probes: Who had it?

What symptoms did they/you have?

What was life like while they/you were sick?

When they/you were having symptoms, were they/you able to stay home and away from other people?

Did they/you take any other steps to protect other people from getting sick?

Did they/you try to get tested? If yes, did they/you test positive?

How are they/you doing now?

Q. [If Wave 1 Interview: Since we talked to you in May:] Have any of your extended family members or close friends had the Coronavirus/COVID-19?

Probes: $\quad$ Can you tell me about them? (relationship to respondent, age, gender, other underlying health conditions)

What symptoms did they have?

When they were having symptoms, were they able to stay home and away from other people?

How are they doing now?

Did they try to get tested? If yes, did they test positive?

Did you interact with them around the time when they had it?

Q. Are you worried about getting the virus (or getting it again)?

Probes: How serious do you think this virus is?

Are you worried about members of your family getting the virus (or getting it again)?

Has anyone in your household been feeling sick? If so, what did you do? What would you do if you thought someone in your household might have Coronavirus/COVID-19?

Q. Now I'm going to ask about some specific things your family may have been doing over the past few weeks. I'm interested in hearing more about what decisions you've made about these kinds of things, how you've made those decisions, and what you're telling your kids about those decisions.

Probes: Getting together with other people you know

(Who? Where? Inside or outside? Masked or unmasked? How distant?)

Going to public places like stores, malls, restaurants, playgrounds

(How often? Inside or outside? Masked or unmasked? How distant?)

Attending large gatherings like religious services, weddings, parties, concerts

(How often? Inside or outside? Masked or unmasked? How distant)

Traveling

(Where? To see whom? By car/air? Masked or unmasked? How distant?) 
Q. Thinking about the things your family has been doing over the past few weeks - do you and your spouse/partner (or your child's other parent) ever have different ideas about what is safe to do during the pandemic?

Probes: If so, can you tell me more about that?

How did you decide?

Q. Public health experts have made a lot of recommendations about what people should be doing to protect themselves and others during this pandemic. What do you think about ?

Probes: $\quad$ Mask wearing

Avoiding close contact with other people

Avoiding public places

Avoiding gatherings of more than 10 people

Working from home if possible

Q. How have you decided which steps to take to keep your family or other people safe?

Probes: Which steps have you taken in the last few weeks? (if not already discussed)

Q. Is there anything that makes it difficult for your family to follow the recommendations from public health experts?

Q. Do you and your spouse/partner ever have different ideas about recommendations from public health experts or about which steps to take to keep your family or other people safe?

Probes: [If yes] What kinds of things have you disagreed about?

[If no] How do you come to agreement on what to do? 
Appendix B: Parents' Likelihood of Reporting Intentions to Vaccinate/Not Vaccinate their Children Against COVID-19 and Parents' Likelihood of Reporting their Children Wore a Mask the Whole Time/Did Not Wear a Mask at All the Last Time They Were in Public (Odds Ratios)

\begin{tabular}{|c|c|c|c|c|}
\hline & $\begin{array}{c}\text { Very or } \\
\text { somewhat likely } \\
\text { to vaccinate } \\
\text { children }\end{array}$ & $\begin{array}{c}\text { Very or } \\
\text { somewhat } \\
\text { unlikely to } \\
\text { vaccinate } \\
\text { children }\end{array}$ & $\begin{array}{l}\text { Child wore mask } \\
\text { the whole time }\end{array}$ & $\begin{array}{c}\text { Child did not } \\
\text { wear a mask at all }\end{array}$ \\
\hline \multicolumn{5}{|l|}{ main } \\
\hline Gender (Woman) & $\begin{array}{c}0.54^{* * *} \\
(0.08)\end{array}$ & $\begin{array}{l}1.77^{* * *} \\
(0.28)\end{array}$ & $\begin{array}{c}0.77 \\
(0.11)\end{array}$ & $\begin{array}{c}1.29 \\
(0.18)\end{array}$ \\
\hline \multicolumn{5}{|l|}{ Education } \\
\hline$<\mathrm{BA}$ & $\begin{array}{c}0.55^{* * *} \\
(0.08)\end{array}$ & $\begin{array}{l}1.72^{* * *} \\
(0.27)\end{array}$ & $\begin{array}{l}0.66^{* *} \\
(0.09)\end{array}$ & $\begin{array}{l}1.51^{* *} \\
(0.21)\end{array}$ \\
\hline Advanced Degree & $\begin{array}{l}1.58^{* *} \\
(0.27)\end{array}$ & $\begin{array}{c}0.91 \\
(0.21)\end{array}$ & $\begin{array}{c}1.23 \\
(0.23)\end{array}$ & $\begin{array}{c}0.81 \\
(0.15)\end{array}$ \\
\hline \multicolumn{5}{|l|}{ Race } \\
\hline Hispanic/Latino & $\begin{array}{c}0.57^{* *} \\
(0.11)\end{array}$ & $\begin{array}{c}1.24 \\
(0.28)\end{array}$ & $\begin{array}{c}0.84 \\
(0.17)\end{array}$ & $\begin{array}{c}1.19 \\
(0.24)\end{array}$ \\
\hline Black & $\begin{array}{l}0.47^{* *} \\
(0.12)\end{array}$ & $\begin{array}{l}2.19^{* * *} \\
(0.50)\end{array}$ & $\begin{array}{c}1.06 \\
(0.23)\end{array}$ & $\begin{array}{c}0.95 \\
(0.21)\end{array}$ \\
\hline Other race & $\begin{array}{l}1.06 \\
(0.21)\end{array}$ & $\begin{array}{c}0.70 \\
(0.16)\end{array}$ & $\begin{array}{c}1.12 \\
(0.22)\end{array}$ & $\begin{array}{l}0.89 \\
(0.17)\end{array}$ \\
\hline \multicolumn{5}{|l|}{ Income } \\
\hline Less than $\$ 25,000$ & $\begin{array}{c}0.57^{*} \\
(0.14)\end{array}$ & $\begin{array}{c}1.69 \\
(0.45)\end{array}$ & $\begin{array}{c}1.51 \\
(0.38)\end{array}$ & $\begin{array}{c}0.66 \\
(0.17)\end{array}$ \\
\hline$\$ 25,000$ to $\$ 49,999$ & $\begin{array}{l}0.52^{* * *} \\
(0.10)\end{array}$ & $\begin{array}{l}1.88^{* *} \\
(0.40)\end{array}$ & $\begin{array}{c}1.12 \\
(0.21)\end{array}$ & $\begin{array}{c}0.89 \\
(0.17)\end{array}$ \\
\hline$\$ 50,000$ to $\$ 74,999$ & $\begin{array}{l}0.65^{*} \\
(0.11)\end{array}$ & $\begin{array}{c}2.03^{* * *} \\
(0.41)\end{array}$ & $\begin{array}{c}0.87 \\
(0.15)\end{array}$ & $\begin{array}{c}1.14 \\
(0.20)\end{array}$ \\
\hline$\$ 75,000$ to $\$ 99,999$ & $\begin{array}{c}0.90 \\
(0.17)\end{array}$ & $\begin{array}{c}1.50 \\
(0.31)\end{array}$ & $\begin{array}{c}1.07 \\
(0.20)\end{array}$ & $\begin{array}{c}0.94 \\
(0.17)\end{array}$ \\
\hline Married/cohabiting & $\begin{array}{c}0.79 \\
(0.14)\end{array}$ & $\begin{array}{c}1.33 \\
(0.28)\end{array}$ & $\begin{array}{c}1.18 \\
(0.22)\end{array}$ & $\begin{array}{c}0.85 \\
(0.15)\end{array}$ \\
\hline \multicolumn{5}{|l|}{ Pandemic employment } \\
\hline Part time & $\begin{array}{c}0.90 \\
(0.23)\end{array}$ & $\begin{array}{c}1.22 \\
(0.30)\end{array}$ & $\begin{array}{c}1.20 \\
(0.29)\end{array}$ & $\begin{array}{c}0.84 \\
(0.20)\end{array}$ \\
\hline Not working & $\begin{array}{c}1.15 \\
(0.23)\end{array}$ & $\begin{array}{c}1.13 \\
(0.21)\end{array}$ & $\begin{array}{c}1.02 \\
(0.18)\end{array}$ & $\begin{array}{c}0.98 \\
(0.17)\end{array}$ \\
\hline $\mathrm{R}$ has had COVID & $\begin{array}{c}0.84 \\
(0.13)\end{array}$ & $\begin{array}{l}1.62^{* *} \\
(0.28)\end{array}$ & $\begin{array}{c}0.84 \\
(0.13)\end{array}$ & $\begin{array}{c}1.20 \\
(0.18)\end{array}$ \\
\hline \multicolumn{5}{|l|}{ Region } \\
\hline Midwest & $\begin{array}{c}0.77 \\
(0.14)\end{array}$ & $\begin{array}{c}1.44 \\
(0.32)\end{array}$ & $\begin{array}{c}0.63^{*} \\
(0.12)\end{array}$ & $\begin{array}{c}1.58^{*} \\
(0.30)\end{array}$ \\
\hline South & $\begin{array}{c}0.74 \\
(0.13)\end{array}$ & $\begin{array}{c}1.39 \\
(0.28)\end{array}$ & $\begin{array}{c}0.89 \\
(0.16)\end{array}$ & $\begin{array}{c}1.12 \\
(0.20)\end{array}$ \\
\hline West & $\begin{array}{c}0.92 \\
(0.18)\end{array}$ & $\begin{array}{c}1.49 \\
(0.33)\end{array}$ & $\begin{array}{c}0.74 \\
(0.14)\end{array}$ & $\begin{array}{c}1.36 \\
(0.26)\end{array}$ \\
\hline Network COVID impact & $\begin{array}{l}1.57^{* * *} \\
(0.21)\end{array}$ & $\begin{array}{c}0.94 \\
(0.15)\end{array}$ & $\begin{array}{c}0.99 \\
(0.14)\end{array}$ & $\begin{array}{c}1.01 \\
(0.14)\end{array}$ \\
\hline
\end{tabular}




$\begin{array}{lcccc}\text { Independent/Other } & 0.48^{* * *} & 1.88^{* *} & 0.63^{*} & 1.58^{*} \\ & (0.08) & (0.39) & (0.12) & (0.29) \\ \text { Repub/Lean Repub } & 0.34^{* * *} & 3.24^{* * *} & 0.43^{* * *} & 2.33^{* * *} \\ & (0.05) & (0.55) & (0.06) & (0.35)\end{array}$

Observations

Exponentiated coefficients; $t$ statistics in parentheses ${ }^{*} p<0.05,{ }^{* *} p<0.01,{ }^{* * *} p<0.001$ 
Figure 1. Opposition to School-Required Immunizations against COVID-19 and School Mask Mandates

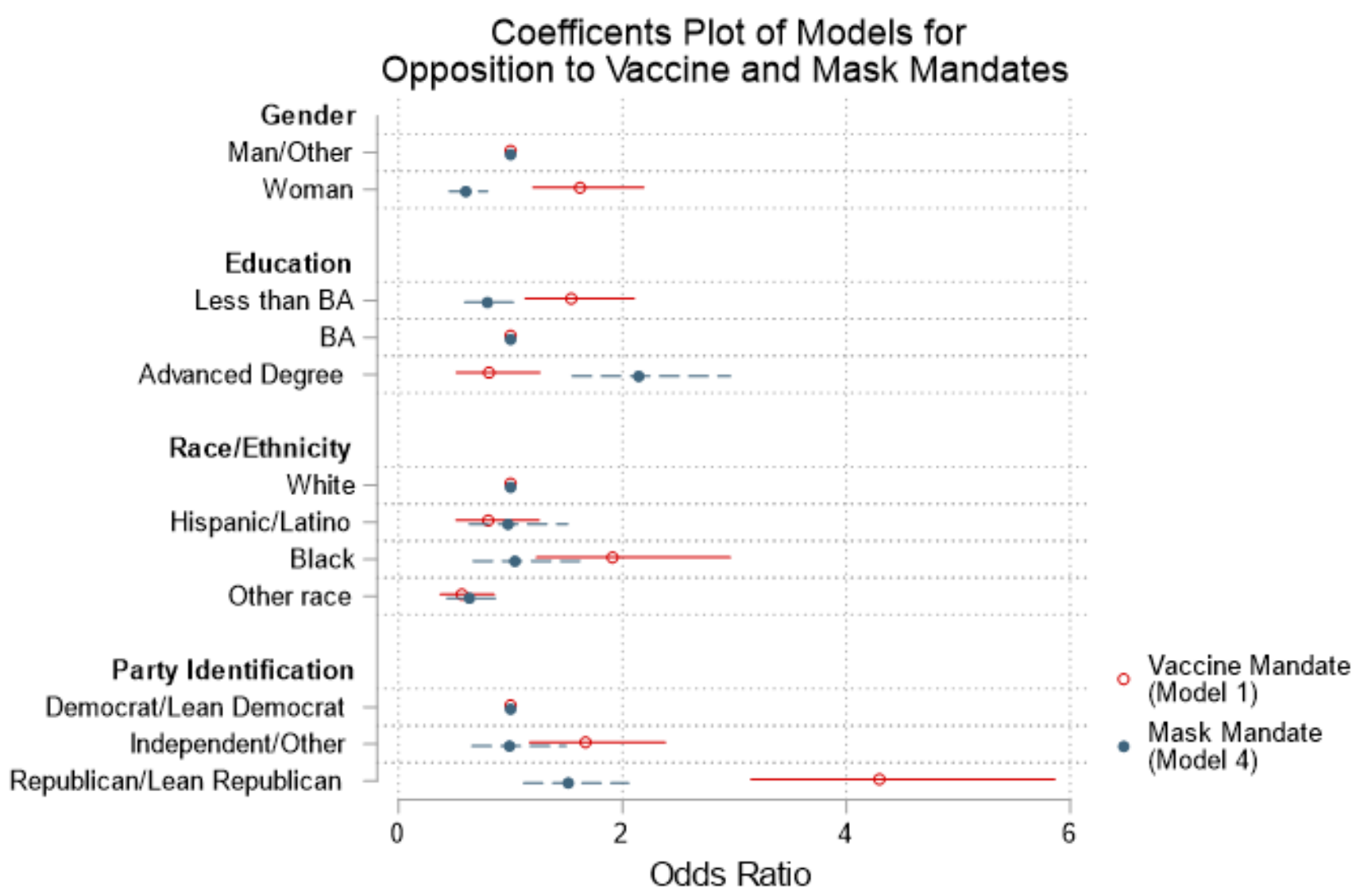

